MR DAVID J ENSING (Orcid ID : 0000-0003-2903-1209)

Article type : Regular Article

\title{
Interannual variation in season length is linked to strong co-gradient plasticity of phenology in a montane annual plant
}

David J. Ensing*, Christopher G. Eckert

Department of Biology

Queen's University

Kingston, Ontario

K7L 3N6

Canada

*Author for correspondence:

E-mail: djensing@gmail.com

Telephone: +1-403-763-0002

ORCID: https://orcid.org/0000-0003-2903-1209

Received: 14 March 2019

Accepted: 10 June 2019

This article has been accepted for publication and undergone full peer review but has not been through the copyediting, typesetting, pagination and proofreading process, which may lead to differences between this version and the Version of Record. Please cite this article as doi: 10.1111/nph.16009

This article is protected by copyright. All rights reserved. 


\section{Summary}

- Species are commonly distributed along latitudinal and elevational gradients of growing season length to which they might respond via phenotypic plasticity and / or adaptive genetic differentiation. However, the relative contribution of these processes and whether plasticity, if it occurs, facilitates expansion along season length gradients remains unclear but are important for predicting species fates during anthropogenic change.

- We quantified phenological trait variation in the montane annual Rhinanthus minor for three generations at 12 sites across $900 \mathrm{~m}$ of elevation in the Canadian Rocky Mountains and conducted a reciprocal transplant experiment for two generations among nine sites. We compared clines and interannual variation of phenological traits between natural and transplanted individuals.

- Season length declined by 37\% along our elevational gradient and, as expected, plants emerged, reached first flower and made their first seed in $~ 41 \%$ fewer growing degree days under shorter growing seasons. Although reciprocal transplants revealed modest genetic differentiation across elevation, trait clines were primarily due to striking co-gradient plasticity that paralleled genetic differentiation.

- Co-gradient plasticity likely evolved in response to considerable interannual variation in season length across our elevational transect, and should prepare $R$. minor to make adaptive changes to phenology in response to ongoing climate change predicted for montane environments.

Key words: co-gradient plasticity, elevation, genetic differentiation, reproductive phenology, range limit, reciprocal transplant, Rhinanthus minor, season length 


\section{Introduction}

As nascent species expand their distributions, they encounter environmental gradients in abiotic and biotic factors to which they respond through phenotypic plasticity or genetic differentiation via incremental local adaptation. Expansion probably first involves plasticity, facilitating persistence beyond the range edge, followed potentially by adaptation (Pigliucci, 2001; Chevin \& Lande, 2011). One of the most predictable environmental gradients involves variation in growing season length, as temperature and the duration of conditions suitable for growth regularly decline with increasing latitude or elevation (Körner, 2007; De Frenne et al., 2013). Expansion into shorter growing seasons at high latitude or elevation is expected to favour more rapid development and reproduction. The relative importance of plasticity vs. adaptive genetic differentiation in phenology for allowing range expansion along season length gradients is crucial for anticipating the responses of species to ongoing environmental change (Conover \& Schultz, 1995; Eckhart et al., 2004; Conover et al., 2009; Münzbergová et al., 2017) but is not well understood (Anderson et al., 2012).

An individual encountering novel environments (e.g. progeny dispersed beyond the current range margin) will likely respond plastically, and the direction of plasticity will determine initial success (Pigliucci, 2001; Ghalambor et al., 2007). Consider the difference in optimal phenotype between two environments the "trait distance", while the difference in phenotype between a genotype planted in the two environments is the "trait shift". Plasticity might shift phenology away from the optimum phenotype (trait shift and trait distance are in opposite directions). Following Eckhart et al. (2004) we define this as counter-gradient plasticity (i.e. non-adaptive plasticity, Ghalambor et al., 2007; Fig. 1f). In contrast, cogradient plasticity allows the colonizing genotype to approach or match the phenotype favoured in the new environment (shift $\sim$ distance, adaptive plasticity, Fig. 1d). Because the optimum trait value is usually not known with certainty, co-gradient plasticity is operationally defined by the plastic response being in the same direction as the phenotypic cline or better yet the genetic trait cline assayed in a common environment (Soularue \& Kremer, 2012). Counter-gradient plasticity, then, is a plastic response in the opposite direction. If conditions beyond the margin reduce fitness, as one might expect if the range limit reflects the niche limit (Hargreaves et al., 2014), the novel environment could slow 
growth, resulting in counter-gradient plasticity (Fig. 1f). For instance, individuals experiencing colder, shorter growing seasons might develop more slowly, thereby delaying reproduction and reducing fitness. Alternatively, if interannual variation in season length at any given position on the gradient reflects season length variation across the gradient, cogradient plasticity may be favoured. For example, a plastic reduction in time to reproduction during years with shorter, colder seasons may be selected within sites, resulting in cogradient plasticity when genotypes disperse towards the shorter end of a growing season gradient. If co-gradient plasticity is likely to evolve when temporal variation reflects spatial variation along the gradient, counter-gradient plasticity is likely when year-to-year variation is low, when the season-length cues within sites are different from those among sites, or when different selective pressures act on the same trait at different locations on the gradient (Kremer et al., 2014). We are unaware of studies testing these predictions.

By influencing selection on the direction of plasticity, the patterns of temporal vs. spatial variation may determine the extent of local adaptation along season-length gradients. It is widely recognized that phenotypic plasticity may shield genotypes from selection (Ghalambor et al., 2007) but co-gradient plasticity may also erode adaptive genetic differentiation in phenology by facilitating gene flow among populations across the gradient (Weis \& Kossler, 2004; Soularue \& Kremer, 2012). This interaction between plasticity and selection may explain why a growing body of research involving elevational and latitudinal gradients has found inconsistent responses of phenological and other functional traits to variable season length (e.g. Olsson \& Ågren, 2002; Etterson, 2004; Sexton et al., 2011; Halbritter et al., 2015, 2018; Kooyers et al., 2015). For instance, a meta-analysis of common garden studies revealed that the predicted acceleration of phenology among populations from short growing seasons at high elevation only occurred in $7.8 \%$ of tests ( 5 of 64 tests with significant, positive slopes, Halbritter et al., 2018). While experiments involving single common gardens can indicate the pattern of genetic differentiation among "source" populations, they do not reveal the magnitude or direction of plasticity. The plastic response can be estimated by comparing differentiation in a common garden with phenotypic clines observed among natural populations across the environmental gradient (Montague et al., 2008; Alberto et al., 2011; Soularue \& Kremer, 2012; Pfennigwerth et al., 2017), but such studies are rare. Better still, plasticity and genetic differentiation can be jointly estimated using reciprocal transplants across season-length gradients (Kawecki \& Ebert, 2004).

This article is protected by copyright. All rights reserved. 
Phenotypic variation among source populations planted at their home site provides a quantitative description of the phenotypic cline and, because planting sites are common gardens distributed along the gradient, variation in phenotype among sources and across sites can be decomposed into genetic differentiation (the source effect) and plasticity (the site effect).

Variation among source populations in the pattern of plasticity across sites in a reciprocal transplant experiment (the source $\times$ site interaction) suggests genetic differentiation in the plastic response among populations, which could occur if some populations experience more temporal variation in season length than others. For instance, populations at range edges may experience more variable environments than relatively central populations (Chevin \& Lande, 2011; Lázaro-Nogal et al., 2015). It is also likely that edge populations experience stronger fitness variation in response to a given amount of environmental variation (Fig. 2). In contrast, cold, short growing seasons at high elevational or latitudinal limits might select for genetically canalised phenology to ensure successful reproduction under strict time constraints (Keller \& Körner, 2003; Gugger et al., 2015). Although reciprocal transplant experiments can reveal much about adaptive trait differentiation as well as the magnitude, direction and variability of plasticity, most experiments focus on fitness variation to estimate local adaptation (i.e. the home site advantage). Occasionally, single phenological traits are measured (usually initiation of flowering, Munguía-Rosas et al., 2011) but rarely do these studies consider the system of interrelated traits that comprise an individual's phenological phenotype (Haggerty \& Galloway, 2011). This is an important gap in our understanding of how phenology evolves in response to changing environments.

As species expand their ranges along environmental gradients, distributional limits occur where adaptation and / or plasticity fail to enable population persistence. The mechanisms that impose current range limits may also influence range expansion under climate change (Kirkpatrick \& Barton, 1997; Ghalambor et al., 2007; Conover et al., 2009). As argued above, co-gradient plasticity may facilitate range expansion whereas countergradient plasticity may forestall it, thereby reinforcing range limits. That the direction of phenological plasticity, in particular, might influence gene flow across the gradient (Weis \& 
Kossler, 2004; Yamagishi et al., 2005) is particularly relevant for range limits (Levin, 2009). Gene flow can, in theory, impede or facilitate adaptation to edge conditions (Holt \& Gomulkiewicz, 1997; Kirkpatrick \& Barton, 1997; Barton, 2001; Bridle \& Vines, 2007) and gene flow from central to marginal populations may feedback to select for stronger cogradient plasticity in marginal populations if immigrants are typically maladapted (i.e. from the centre, Chevin \& Lande, 2011; see also Weis, 2015). However, we know little about the patterns and mechanisms of variation in key phenological traits towards species range limits (Eckert et al., 2008) and hence the likelihood of significant feedback with the evolutionary factors that constrain range expansion. Here, we combine natural population surveys and replicated, reciprocal transplants to investigate the patterns and sources of variation in lifetime reproductive phenology using the annual plant Rhinanthus minor L. (Orobanchaceae) distributed across elevation to its upper elevational range limit in the Canadian Rocky Mountains. In southern Alberta, this species is commonly found in open meadow habitat from the foothills and valley bottoms ( 1100 metres above sea level (masl)) to above the treeline (2340 masl). As a diminutive ( $<80-\mathrm{cm}$ tall), annual herb, seeds germinate after snowmelt and plants complete their life cycle within the same summer, facilitating multigenerational studies and quantification of all aspects of reproductive phenology (Westbury, 2004). Rhinanthus minor produces relatively few, large seeds $(<20 /$ fruit, usually $<20$ fruits / plant) with little dormancy (ter Borg, 2005) that are readily planted directly into unmanipulated natural habitat. Although the species is a hemiparasite, it is a host generalist and other biotic interactions are of little importance as it has no mycorrhizal associations, and is predominantly self-fertilizing (Ducarme \& Wesselingh, 2013; Hargreaves et al., 2015). Hence the phenology and fitness of relatively small, experimentally transplanted populations are not affected by the absence of mutualists.

We quantified patterns and sources of phenotypic variation in phenological traits across the elevational distribution of $R$. minor over three generations for naturally occurring populations and two generations for transplanted populations to test five predictions: (1) Growing season length becomes (a) shorter and (b) varies more between years towards the upper elevational limit. (2) The developmental time to emergence, first flowering, and first mature fruit decreases among natural populations in concert with declining season length. (3) The relative contribution of genetic differentiation vs. plasticity to this cline will depend on the direction of plasticity: (3a) Counter-gradient plasticity of phenological traits, wherein the 
phenological trait shift and distance are negatively related, will be associated with significant genetic differentiation in phenological traits among populations across elevation. In contrast, (3b) co-gradient plasticity, wherein the trait shift and distance are positively related, will be associated with relatively low genetic differentiation. (4) Co-gradient plasticity will be associated with interannual variation in season length that parallels the elevational gradient.

(5) Plasticity will increase toward the range margin to cope with increasingly variable environments (Fig. 2).

\section{Materials and Methods}

\section{Study design}

We studied $R$. minor in Kananaskis Country, Alberta, Canada from valley bottom to alpine, spanning $\sim 1000$ m elevation (climatically equivalent to a latitudinal change of $\sim 8.5^{\circ}$ or $\sim 930$ km due north, Nagy \& Grabherr, 2009; La Sorte et al., 2014). In 2014, we selected 12 sites where $R$. minor naturally occurred along three east-facing elevational transects from 14502340 masl (T1-T3, Supporting Information Notes S1). The highest sites on T2 and T3 were at the species' upper range limit (T2: 2310 masl, T3: 2340 masl; elevation quantified using a Garmin GPSMap 60 Cx; Garmin, Olathe, Kansas, USA), where apparently suitable, open meadow habitat occurred contiguously at higher elevation (Fig. S1.1 in Notes S1). T1 ended at 2206 masl below a sheer, rocky cliff face. At each site we selected 30 plots with $R$. minor for phenological and environmental analysis, and repeated the study in 2014, 2015 and 2016.

\section{Elevational clines in season length and environment}

Elevation may not be a reliable proxy for growing season length because mountain climates also depend on aspect, slope, and shading (Körner, 1999; Beniston, 2005; Nagy \& Grabherr, 2009). We quantified season length at each site based on growing degree days (GDD), a measure that quantifies the accumulation of biologically relevant heat units (Körner, 2007). We calculated GDD as the daily average of hourly temperatures above a baseline temperature of $5^{\circ} \mathrm{C}$. Hours with temperatures below $5^{\circ} \mathrm{C}$ were assigned $0 \mathrm{GDD}$, while those above $25^{\circ} \mathrm{C}$ were assigned 25 GDD (Miller et al., 2001). Results were not sensitive to the baseline 
temperature used (Notes S2). Hourly GDD were summed for each day and divided by 24 . At each site, we recorded hourly temperatures year-round with 1-7 temperature probes $($ mean $=$ 3.5; Notes S2). Because we initiated the study in May 2014, loggers were not deployed until late spring, so we reliably estimated hourly temperatures at each site for early spring 2014 using nearby weather stations in the Changing Cold Regions Network (Fig. S1.1 in Notes S1; Notes S3).

We defined season length in three ways, (1) the annual accumulation of GDD (AnGDD); (2) GDD accumulated from the beginning to the end of the growing season (limits defined below, GsGDD); and (3) the number of days during the estimated growing season (GsDays). AnGDD makes no assumptions about when the growing season starts and ends. The start and end of the growing season (for GsDays and GsGDD) were estimated as the first and last date that mean temperature in a 6-day sliding window was $>4^{\circ} \mathrm{C}$, which matched observed snow melt and plant community phenology in the field (Notes S4).

\section{Natural clines in phenology}

In each of 30 plots per site, we randomly selected five seedlings ( $n=150$ plants/site) as they emerged in May, and measured observable vegetative and reproductive traits every $\sim 5^{\text {th }}$ day until senescence. If plants died before first flower, they were replaced by a randomly-selected pre-flowering individual in the same plot. Because replacement plants were always preflowering, their inclusion could bias our results toward later flowering individuals. However, replacement plants flowered an average of only 4.4 GDD later and this was not significant for 32 of 36 year $\times$ site combinations ( 2 -sample $t$-tests, mean $P=0.41)$. We measured phenology at critical of life history junctures, including emergence from seed, initiation of flowering, and first mature fruit (prediction 2). Emergence was estimated from the date each plant reached three leaf nodes (measured for $94 \%$ of initial marked individuals) because we could only access sites after seeds had begun to germinate. We quantified both accumulated GDD and days from the beginning of the season to first flower, the beginning of the season to first mature fruit, from emergence to first flower, and first flower to first fruit. Because we visited individuals every $\sim 5^{\text {th }}$ day, emergence, first flower, or first fruit may have occurred between 
visits. We therefore inferred dates for phenological events not directly observed (i.e. we used flower number on the date of first flower observation to estimate the date that the first flower opened; Notes S4).

\section{Sources of phenological variation in reciprocal transplants}

To quantify the contribution of genetic differentiation and phenotypic plasticity to the observed phenotypic clines, we reciprocally transplanted seed collected from naturallyoccurring monitored individuals at nine of the 12 sites (Mid-low sites excluded from all three transects, Notes S1). The transplants occupied all suitable habitat at T3-High, so we added a $13^{\text {th }}$ site (T3-Marmot High) to estimate of natural variation in 2015 and provide seed for the 2016 transplants. We planted seeds in September 2014 and 2015 and monitored the emerging seedlings through their lifespans during the following growing seasons. All seeds were planted $\leq 40 \mathrm{~d}$ after harvest $\leq 5 \mathrm{~mm}$ below the soil surface to experience environments similar to naturally dispersed seeds, which simply fall from the maternal plant to the ground. Transplant blocks ( $2 \times 2 \mathrm{~m}$ ) were located in patches of habitat with naturally-occurring $R$. minor, which were removed before fruit maturation in the planting year. Within each block, seeds were planted in $25 \times 25 \mathrm{~cm}$ grids, spaced $30 \mathrm{~cm}$ apart and $>30 \mathrm{~cm}$ from adjacent block edges to reduce contamination by seed from natural plants outside the block.

The 2015 experiment was not fully reciprocal due to insufficient seed (Notes S1). At each site we planted seeds from that site, and the three sites from each of the other two transects (seven source populations per site). Seeds from each source were pooled and planted in a grid of 16 seeds (four by four seeds, one source per grid) in each of 10 blocks per site ( $n=10080$ seeds planted). The 2016 transplant experiment was fully reciprocal, with nine grids of 12 seeds $(3 \times 4$, each row of 4 planted with seed from a single randomly selected seed family) in each of 15 new blocks per site (prepared as in 2015, $n=14580$ seeds planted). Transplants were monitored as above for natural individuals. Because we used field collected seed, phenotypic variation among source populations may be due to a combination of genetic differentiation and non-genetic maternal effects, which we acknowledge in our discussion below.

This article is protected by copyright. All rights reserved. 


\section{Statistical Analysis}

Elevational variation in season length

Does season length decline with increasing elevation (prediction 1a)?

We quantified covariation of season length and elevation (prediction 1a) by fitting each of our three measures of season length to mixed-effects models with the lmer function in the lme4 package (version 1.1-18-1, Bates et al., 2015) in the R statistical environment (R Core Development Team, 2018). We predicted growing season length (GSL) with elevation, year and their interaction as fixed predictors; site was included as a random effect in all models. We evaluated seven competing models using corrected Akaike's information criterion (AIC) calculated with the AICc function in the MuMIn package (version 1.42.1, Barton, 2018). The full model included year, elevation, squared elevation, and interactions between year and both elevation terms:

$$
\begin{aligned}
& \mathrm{GSL} \sim\left(\text { elevation + elevation }{ }^{2}\right) * \text { year }+(1 \mid \text { site }) \\
& \mathrm{GSL} \sim \text { elevation }+ \text { elevation }^{2}+\text { year }+(1 \mid \text { site }) \\
& \mathrm{GSL} \sim \text { elevation } * \text { year }+(1 \mid \text { site }) \\
& \mathrm{GSL} \sim \text { elevation + year + }(1 \mid \text { site }) \\
& \mathrm{GSL} \sim \text { elevation }+(1 \mid \text { site }) \\
& \mathrm{GSL} \sim \text { year }+(1 \mid \text { site }) \\
& \mathrm{GSL} \sim 1+(1 \mid \text { site })
\end{aligned}
$$

Models were considered different if their AICc values differed by $>2$. Elevation was centred by subtracting the mean for the quadratic terms to reduce collinearity with its linear term. Model fit was quantified using the r.squaredGLMM function (see Nakagawa \& Schielzeth, 2013; Johnson, 2014) in MuMIn. For all statistical analyses, we graphically confirmed that residuals were close to normally distributed and independent from fitted values.

This article is protected by copyright. All rights reserved. 
Does season length become more variable toward the range margin (prediction $1 b$ )?

We tested whether the relative among-year variation in season length, measured as the standard deviation (SD) among years, varied with elevation or mean season length (prediction $1 \mathrm{~b}$ ) by fitting a linear regression using the $1 \mathrm{~m}$ function. We dropped T3-Marmot high from this analysis because it only had two estimates of season length (2015 and 2016).

\section{Natural clines in phenology}

Does development time decrease with declining season length (prediction 2)?

Using lmer and AICc (as above), we compared seven competing models for the relation between each phenological trait and growing season length (GSL), with site and block within site as random effects. The full model included year, GSL, centered and squared GSL and interactions between year and both GSL terms:

$$
\begin{aligned}
& \text { Trait } \sim\left(G S L+\mathrm{GSL}^{2}\right) * \text { year }+(1 \mid \text { site } / \text { block }) \\
& \text { Trait } \sim \text { GSL }+\mathrm{GSL}^{2}+\text { year }+(1 \mid \text { site/block }) \\
& \text { Trait } \sim \text { GSL } * \text { year }+(1 \mid \text { site/block }) \\
& \text { Trait } \sim \text { GSL + year + (1| site/block }) \\
& \text { Trait } \sim \text { GSL + (1|site/block }) \\
& \text { Trait } \sim \text { year }+(1 \mid \text { site/block }) \\
& \text { Trait } \sim 1+(1 \mid \text { site/block })
\end{aligned}
$$

Sources of phenological variation in reciprocal transplants

Because the transplant design differed among years (above), we analyzed each year separately, and excluded source $\times$ site $\times$ year combinations where $<5$ plants reached a given phenological stage (9 of 144 for first flower [including all seven sources at T1-L in 2015], 37 for first fruit but none for emergence). 
Does the relative contribution of genetic differentiation $v$ s. plasticity depend on the direction of plasticity (prediction 3)?

To test for potential genetic differentiation in phenological traits among source populations and plastic responses to environmental variation among sites (prediction 3), we used lmer to fit variation in each of the phenological traits to a mixed-effects model including source population and planting site as fixed effects and block nested within site as a random effect. Competing models were evaluated with AICc. We interpret a significant effect of site as evidence of plasticity, and a significant effect of source as evidence of genetic differentiation (or maternal effects). We evaluated the relative influence of source $(\mathrm{P})$ by dividing the source sums-of-squares $\left(\mathrm{SS}_{\mathrm{P}}\right)$ by the total $\mathrm{SS}\left(\mathrm{SS}_{\mathrm{P}}+\mathrm{SS}_{\mathrm{D}}\right.$, where $\mathrm{D}$ is destination site). When genetic differentiation was suggested by the results, we examined its clinal nature by regressing each source population's phenotype (within each destination site, D) against its 'home' season length (averaged across years) and included planting site and the interaction between site and season length as fixed effects. Because the experiment was fully crossed in 2016 (all sources planted at all sites), we could also test the interaction between source and site. A significant interaction would suggest that the expression of phenotypic differentiation among sources varied among planting sites and the expression of plasticity varied among source populations.

Prediction 3 concerns the direction of the plastic response of transplanted seed. To test whether the plastic phenological responses of a given source population matched (prediction $3 b$ ) or opposed (prediction 3a) phenotypic variation in phenology across the season length gradient, we regressed the mean phenotype of each source over annual growing season length at each planting site and included source population and the interaction as fixed effects. Cogradient plasticity would be indicated if the effect of planting site season length on phenology was in the same direction as the phenotypic cline and counter-gradient plasticity if it was opposite.

Finally, we evaluated the extent to which plasticity allowed transplanted populations to match the phenotypes of resident populations (the putative selective optima). We quantified the phenotypic shift as the difference between the phenotype of a focal transplanted source $(T)$ at its home site $\left(T_{h}\right)$ and at a given destination site $\left(T_{d}\right)$. Similarly, we quantified the phenotypic distance (D) as the difference in phenotype between the 
transplanted source planted at home $\left(\mathrm{T}_{\mathrm{h}}\right)$ and the resident phenotypes at the destination site (i.e. its home site: $D_{h}$ ). We then regressed T over D. Points lying on the 1:1 line (phenotypic shift $=$ phenotypic distance, Fig. 1d) represent full, co-gradient plasticity such that transplanted populations matched the resident phenotype, while points lying along a horizontal line at 0 on the phenotypic shift axis suggests no plasticity and considerable genetic differentiation (Fig. 1e). Points around a negative 1:1 line indicate perfect countergradient plasticity (Fig. 1f). We estimated the slope (and 95\% CIs) of phenotypic shift regressed over phenotypic distance with major axis model II regression implemented in the lmodel2 package (version 1.7-3, Legendre, 2018).

\section{Does interannual variation in season length contribute to co-gradient plasticity (prediction 4)?}

To test prediction 4, we examined the association between variability in season length and variability in phenology across the three study years. We used major axis model II regression, as above, to estimate the relation between pairwise difference in season length between years and the pairwise shift in each site's mean phenology between years. The 95\% confidence intervals of the slope were estimated by a permutation test (9999 permutations) to account for nonindependence of the data.

\section{Does plasticity increase toward the range margin (prediction 5)?}

Given significant plasticity (prediction 3), we were particularly interested in whether responses (i.e. slopes) were stronger for populations towards the upper elevation range limit. A significant interaction between mean source phenotype and destination season length would indicate that plasticity varied among source populations. If interactions were significant, we estimated the standardised slope for each source and then regressed these slopes over the gradient of mean source season length.

This article is protected by copyright. All rights reserved. 


\section{Results}

\section{Elevational variation in season length}

Does growing season length decline with elevation (prediction 1a)?

Consistent with prediction 1a, all three measures of growing season length declined with increasing elevation and varied significantly among years (Fig. 3, Table S4.1 in Notes S4). Comparing the lowest ( 1450 masl) vs. highest elevation sites ( 2340 masl), season length declined by $\sim 37 \%, 47 \%$ and 30\% as measured by AnGDD, GsGDD and GsDays, respectively (mean standardised slope $=-0.75$, Table S4.1 in Notes S4). AnGDD correlated tightly with GsGDD (Pearson's $r=+0.94, P<0.001$ ) and GsDays $(r=+0.91, P<0.001$ ). Because AnGDD makes no assumptions about growing season limits and recognises that opportunities for growth and reproduction vary with temperature across elevation, we present AnGDD as the measure of season length in the analyses below and Notes S6 (see later) (key results using GsDays are in Notes S7, see later).

Does season length become more variable toward the range margin (prediction 1b)?

Among-year variability in growing season length was considerable (prediction 4), and increased with mean $\operatorname{AnGDD}\left(F_{1,9}=13.44, P=0.0052\right)$. Contrary to prediction $1 \mathrm{~b}$, however, among-year variability in growing season length did not vary with elevation $\left(F_{1,9}=1.03, P=\right.$ 0.34). For instance, AnGDD at T1-ML (1773 masl) was 1158 in 2014 but increased to 1356 in 2015. That 200 GDD increase is equivalent to moving those plants (based on the 2015 regression coefficients) downslope to $1469 \mathrm{~m}$, or just above the T1-L site (Table S1.1 in Notes S1).

\section{Natural clines in phenology}

Does development time decrease with declining season length (prediction 2)?

Of the naturally occurring plants initially monitored $(n=5420), 43 \%$ survived to first flower and $24 \%$ to first mature fruit (Notes S5). Consistent with prediction 2, all phenological traits declined strongly with decreasing growing season length (> 30\% decline from greatest-to- 
least AnGDD for all traits, Fig. 4, Table 1) and all traits varied among years. Clines were steep for AnGDD to emergence, first flower, and first mature fruit, and somewhat weaker for emergence to first flower (Table 1). For all traits except emergence to first flower, the slope of the regression over AnGDD varied significantly among years but never approached zero or reversed direction (Fig. 4).

\section{Sources of phenological variation in reciprocal transplants}

Of the 24660 seeds planted across the nine experimental sites and both years, $26 \%$ emerged, $51 \%$ of those survived to first flower, and $28 \%$ survived to first fruit (Table S5.2 in Notes S5). We detected significant variation among both sites and source populations in both years for AnGDD to emergence, emergence to first flower, AnGDD to first flower, and AnGDD to first mature fruit. AnGDD from first flower to first mature fruit only varied among sites (Table S6.1 in Notes S6). Source x site interactions were not significant. Based on the sums of squares for the effect of source population vs. planting site, the contribution of variation among source populations to phenological variation was low to modest compared to the effect of planting site (mean $=0.186$, range $=0.022$ to 0.438 , Table S6.1 in Notes S6). The effects of source population were largest for GDD to first flower and emergence to first flower, and lowest for first flower to first fruit.

Does the relative contribution of genetic differentiation vs. plasticity depend on the direction of plasticity (prediction 3)?

The clines in phenological traits were due in part to genetic differentiation. Plants from shortseason sites flowered and produced mature fruits in fewer GDD than those from long seasons (Table 2). This was apparent regardless of the season length at the planting site. However, the genetic cline evident within reciprocal transplant sites was much shallower than the phenotypic cline observed among the naturally occurring plants (Fig. 5, compare with Fig. 4).The effect of source population growing season length $\left(S_{P}\right)$ was significant for all traits in 2016, but only for GDD to first flower, first fruit and emergence to first flower in 2015

(Table 2). The slopes of the significant regressions (mean standardized slope $=+0.147$, from Table 2) were much lower than those of the phenotypic clines observed among natural 
populations (mean standardized slope $=+0.672$, from Table 1). Much of the cline in phenological traits appears to due to co-gradient plasticity. Regressions of source population phenotype over the variation in season length among planting sites $\left(\mathrm{S}_{\mathrm{D}}\right)$ were consistently significant (Fig. 6, Table 3), much stronger than source population phenotype over $\mathrm{S}_{\mathrm{P}}$ (Fig. 5, Table 2) and as strong as the phenotypic clines (Fig. 4; mean standardized slope $=+0.802$, from Table 3; prediction $3 b$ ).

Does interannual variation in season length contribute to co-gradient plasticity (prediction 4)?

Model II regression slopes for phenological shift over phenological distance among transplanted populations were strongly positive for all traits (all slopes $>0$ ), indicating cogradient plasticity (Fig. 7). Transplanted populations almost matched the resident population phenotype. However, GDD to first mature fruit was the only trait where the confidence interval of the slope overlapped one. For all other traits, slopes were close to but significantly less than one, indicating somewhat less than perfect phenotype matching.

Consistent with prediction 4, co-gradient plasticity exhibited by transplanted populations was associated with considerable interannual variation in growing season length. Differences in AnGDD between year $\times$ sites ranged from 10.25 to 197.74 and averaged 53.77 GDD, which is equivalent to a $94 \mathrm{~m}$ vertical movement along the elevation gradient (using 2016 regression coefficients). The responses of plants in natural populations to this betweenyear variation paralleled the co-gradient plasticity observed after transplanting but only for GDD to emergence, first flower and first fruit (Fig. 8). The model II slopes for these traits overlapped one, indicating the GDD to reach these phenological events changed by about one GDD for a one GDD change in season length. In contrast, GDD from emergence to first flower and first flower to first fruit did not respond consistently to interannual season length variation.

This article is protected by copyright. All rights reserved. 
Does plasticity increase toward the range margin (prediction 5)?

Contrary to our prediction, the degree of plasticity did not vary among the source populations for any phenological trait (Akaike weights were $<0.0001$ for all models with $\mathrm{S}_{\mathrm{D}} \mathrm{x} P$ interactions in Table 3).

\section{Discussion}

Naturally occurring Rhinanthus minor exhibit a steep cline in reproductive phenology across an elevational season length gradient in the Canadian Rocky Mountains. This cline arises from strong co-gradient plasticity combined with modest genetic differentiation. Based on environmental data measured directly at each site, plants at the high elevation range limit require an average of $41 \%$ fewer growing degree days to emerge, flower, and mature their first fruit than plants at lowest elevation (Fig. 4; prediction 2), and this matched the concomitant $37 \%$ reduction in estimated growing season length (Fig. 3; prediction 1a). We detected what could be adaptive genetic differentiation across the elevational gradient. Genotypes sourced from long season, low elevation sites exhibited slower reproductive phenology than short season, high elevation genotypes, particularly for development to flowering (Table 2). Because we used field-collected seed, maternal effects may have contributed to what seems like adaptive genetic differentiation. Although there are examples of adaptive maternal effects influencing flowering phenology in plants (Galloway \& Burgess, 2009; Wadgymar et al., 2018a), meta-analysis indicates that they are rare (Uller et al., 2013). Possible genetic differentiation, however, was weak compared to strong co-gradient phenological plasticity that enabled genotypes transplanted into a different growing season to almost match resident phenotypes for all key traits (Fig. 7; prediction 3b). As predicted, cogradient plasticity was associated with considerable interannual variation in season length within sites (prediction 4), and the response of plants to temporal variation in season length mirrored their response to spatial variation for some but not all traits. Contrary to expectations, we did not observe greater year-to-year variation in season length towards the upper range limit (prediction $1 \mathrm{~b}$ ), nor did edge populations exhibit greater plasticity (prediction 5).

This article is protected by copyright. All rights reserved. 
Unlike most previous studies on reproductive phenology we used growing degree days (GDD) as a currency of season length rather than time (e.g. days), and our results indicate the value of using a biologically-relevant measure of developmental rate to analyse phenological variation across gradients of growing season length (Wadgymar et al., 2015, 2018b). In our study, GDD was a more appropriate measure of developmental rate than days because heat accumulation per day varies strongly across elevation. In Notes S7, we report the core analyses using days as a developmental currency, which yield similar but more complex patterns of phenotypic variation and differentiation among source populations. However, the plastic response to variation in season length was reversed for days to first flower, emergence to first flower, and first flower to first mature fruit, especially in 2015 (details in S7). The contrast between patterns revealed using the two currencies makes sense given that GDD accumulate more slowly at higher elevation.

\section{Is strong co-gradient plasticity of phenology remarkable?}

Co-gradient plasticity in $R$. minor was strong enough that transplants almost matched the phenology of residents for all traits. This dramatic response would likely buffer populations against rapidly changing climates, but it is not clear how common co-gradient phenological plasticity is among plants. The directionality of phenological plasticity is rarely quantified, and generalizing from the few existing studies is difficult because they express phenology in a few different currencies. We compiled published studies that directly investigated the directionality of plasticity in plants across season length gradients in Table 4. Several studies express phenology as "date of". This may not be a useful measure of developmental rate for comparisons among sites across season length gradients because the growing season usually starts at a later calendar date at higher elevations/latitudes. As a result, studies using this phenological currency often report what seems to be counter-gradient variation ( 3 of 5 cases in Table 4). For example, date of leaf out in natural populations of several European trees increases steeply with latitude (Alnus glutinosa, De Kort et al., 2016; Frangula alnus, Vander Mijnsbrugge et al., 2016) and elevation (Quercus petraea, Fagus sylvatica, Vitasse et al., 2009b). Yet, high latitude genotypes often leaf out before low latitude genotypes when planted in a common garden, which the authors deem counter-gradient variation (following Conover et al., 2009, Table 4). However, comparing direct measures of developmental rate to 
leaf-out between natural clines and common gardens would possibly reveal co-gradient plasticity. Studies using days from the start of the growing season or from one developmental stage to the next compare populations using common temporal landmarks and tend to detect both counter- and co-gradient variation ( 6 and 5 cases, respectively), even among and within closely related species (Toftegaard et al., 2016). Yet, the per-day availability of heat or some other environmental factors that defines season length (e.g. soil moisture) will often vary across season length gradients. To deal with the inadequacies of date and day as units of development rate, we used GDD as a phenological currency because it better represents opportunities for growth and reproduction across elevation, and because experimental warming studies indicate temperature as a limiting factor in montane populations of $R$. minor (Hargreaves \& Eckert, 2019). As discussed above, supplementary analyses of our results (Notes S7) suggest that using days instead of GDD may indicate different patterns of plasticity, a contrast between developmental currencies was also shown by Wadgymar et al. (2015, 2018b). Although using GDD as a phenological currency will tend to capture variation in developmental rate more accurately, it assumes a common linear response of plants to variation in temperature between lower and upper thresholds, and that these temperature thresholds do not vary with season length. A better understanding of how plants respond to large-scale environmental gradients will require phenological measures in the most biologically-relevant units (Forrest \& Miller-Rushing, 2010).

Criteria for classifying the plastic response of a genotype as co-gradient rather than counter-gradient are often based, explicitly or implicitly, on whether plasticity yields a phenotype closer to the optimum in the environment to which the genotype was transplanted. In this study, we followed previous workers in defining plasticity as co-gradient if was in the same direction as the phenotypic cline in phenology among natural plants and the genetic differentiation among source populations across the gradient of growing season length. However, we recognize that average phenotypes in natural populations may not well represent the selective optima (Estes \& Arnold, 2007), and this may be a particularly important issue for flowering phenology because most estimates of selection indicate directional selection for earlier flowering (Munguía-Rosas et al., 2011; discussion in Austen et al., 2017). This issue notwithstanding, transplanted genotypes often closely matched the phenological phenotypes of resident plants through striking phenological plasticity.

This article is protected by copyright. All rights reserved. 


\section{Evolution of phenological plasticity and consequences for adaptive genetic differentiation}

Plasticity should evolve in response to environmental variability over short temporal and spatial scales (Ghalambor et al., 2007). Co-gradient plasticity, in particular, is expected when within-site environmental variation across time correlates positively with spatial variation among sites along the environmental gradient (Chevin \& Lande, 2011). However comparisons of plastic responses to temporal vs. spatial environmental variation are exceedingly rare (Eckhart et al., 2004). On the montane gradient we studied, individual sites experienced year-to-year fluctuations in growing season length on par with the substantial spatial shifts they experienced when moved across elevation. Consistent with theoretical expectations, interannual shifts in season length were associated with phenological adjustments for GDD to emergence, and the two composite traits built upon it: flowering, and fruit maturation. Plants responded similarly to temporal and spatial variation. However, the predicted interannual response did not occur for GDD from emergence to first flower, or first flower to first mature fruit, indicating that the primary plastic response to interannual variation is adjustment of spring phenology. Thus, interannual variation in spring temperatures and plasticity of emergence time prepares local populations for movement along the season length gradient but does not result in changing development rates once growth has begun. Why some phenological traits exhibited co-gradient plasticity when planted among sites at different elevations but not when experiencing different season lengths within sites is not clear. This result suggests that there is climatic variation or associated cues associated with spatial but not temporal variation. For instance, the relation between snow melt and other phenological cues such as photoperiod and, for hemiparasites like $R$. minor, host phenology may influence developmental rate and phenology and vary more across elevation than between years.

Genetic differentiation of phenological traits across season length gradients is expected because phenotypic variation in traits like flowering time (usually measured in days) is frequently heritable (Weis \& Kossler, 2004; Hendry \& Day, 2005), and respond to both natural and artificial selection (Burgess et al., 2007; Franks et al., 2007; Sedlacek et al., 2016). Although montane environments present steep gradients in season length across which the form and strength of natural selection on phenology may vary substantially, these

This article is protected by copyright. All rights reserved. 
elevational gradients are short so that gene flow might oppose adaptive differentiation (Kirkpatrick \& Barton, 1997). Although we detected clinal genetic differentiation (and/or adaptive maternal effects) for some phenological traits in one or more years, it made a minor contribution to phenotypic clines. Recent meta-analysis also found inconsistent genetic differentiation in phenological traits across elevation (Halbritter et al., 2018). In the case of $R$. minor, the most obvious explanation for low genetic divergence is that gene flow across the elevational gradient is promoted by strong co-gradient plasticity (Crispo, 2008; Levin, 2009). Whether gene flow is strong enough to thwart adaptive differentiation is unclear. Genetic differentiation of montane populations despite high gene flow has been documented for other plants species (Gonzalo-Turpin \& Hazard, 2009) and differentiation of phenological traits, in particular, may feedback negatively on the rate of gene flow (Weis \& Kossler, 2004;

Soularue \& Kremer, 2012, 2014; Weis, 2015). Gene flow among montane populations of other species based on genetic markers has sometimes revealed more gene flow between populations at similar elevastion than populations at different elevations (Sexton et al., 2016). In $R$. minor, gene dispersal by pollen is limited by high levels of self-fertilisation (Hargreaves et al., 2015) and the species' large seeds have no obvious mechanism of long-distance dispersal (van Hulst et al., 1986; Westbury, 2004). Moreover, population genetics based on SNPs indicates that genome-wide differentiation among the populations we studied is substantial (mean $F_{\mathrm{ST}}=0.18$; DJ Ensing and CG Eckert, unpublished). Although our results are consistent with the expectation that strong-co-gradient phenological plasticity should be associated with limited genetic differentiation because it enhances gene flow by increasing the success of individuals dispersing along the season length gradient, the mechanisms underlying this association in $R$. minor remain unclear.

\section{Range limits and range expansion in Rhinanthus minor}

Rhinanthus minor reaches a conspicuous upper elevational range limit at 2400 masl in our study area. In fact, extensive field surveys and herbaria records have failed to locate any occurrence of $R$. minor above 2340 masl in the Canadian Rocky Mountains. Previous transplants beyond the upper elevational range limit suggest that this is a hard niche limit imposed by low temperature and a limited growing season. Plants moved just $60 \mathrm{~m}$ above the current range limit failed to produce enough seed for self-replacement $(\lambda<1)$ but warming with open-topped chambers partly alleviated this constraint by accelerating reproductive phenology (Hargreaves \& Eckert, 2019). 
What limits range expansion by $R$. minor given its strong co-gradient plasticity and capacity for seemingly adaptive phenological differentiation across elevation? A likely explanation is that reduced GDD to flowering and fruiting, through co-gradient plasticity or local genetic differentiation, comes at the cost of reduced size at flowering, to the extent that the earliest flowering individuals do not make enough seed for self-replacement (Colautti et al., 2010). Supplementary analysis of our data from both natural plants and experimental transplants does not support this. Neither size at flowering or per-capita seed production decreases with reduced GDD to flowering, either within sites or among sites across the elevational gradient (Ensing, 2019 see also Hargreaves \& Eckert, 2019). This underscores the disconnect between patterns of fitness variation within vs. beyond geographic ranges observed in a wide array of plants and animals (Sagarin et al., 2006). Abrupt changes in the relation between key traits and fitness may be important in causing range limits on continuous ecological gradients, especially when genetic drift is strong (Polechová \& Barton, 2015).

Montane regions are expected to experience among the fastest rates of warming under climate change (Diaz et al., 2003; Nogués-Bravo et al., 2007; La Sorte \& Jetz, 2010) and there is widespread concern that this may put montane and especially alpine species at risk. Moreover, the most prevalent responses to climate change have been phenological adjustments (Parmesan \& Yohe, 2003; Parmesan, 2006) that often move species away from local optima or interfere with interspecific interactions (Inouye et al., 2000; Bradshaw \& Holzapfel, 2008; Miller-Rushing et al., 2010). In contrast, the strong co-gradient plasticity observed in R. minor across elevation in the Rocky Mountains suggests that it is well prepared to take advantage of predicted longer growing seasons under warming (see also Gonzalo-Turpin \& Hazard, 2009). In fact, high / edge source populations transplanted downslope can match, and in some cases outperform resident, low elevation populations (Hargreaves \& Eckert, 2019). It is therefore likely that high elevation populations of $R$. minor will be able to plastically match new optimal trait values when their habitat warms.

This article is protected by copyright. All rights reserved. 


\title{
Acknowledgements
}

We thank our dedicated field teams, D. Sora, L. Redmond, B. Syme, J. Verbeek, E.

Bloomfield, S. Bocchinfuso, S. Rotman, L. Pekrul, N. Ensing, S. Zhu, J. Ensing, L. Ensing, F. Vladimirovna-Ivaniuk, and K. Tillapaugh for all their hard work through 15 months in the field; A. Hargreaves for technical advice and Rhinanthus lore; A. Cunnings at University of Calgary's Biogeoscience Institute Research Station for logistic support; J. Pomeroy (University of Saskatchewan) and the Changing Cold Regions Network for access to their weather station data; E. Austen and M. Johnson for comments on the manuscript; the Natural Sciences and Engineering Research Council of Canada (NSERC) and the Alberta Conservation Association Biodiversity Grant program for grants to CGE; NSERC for a Canada Graduate Scholarship to DJE. This research was conducted on Treaty 7 land, and we gratefully acknowledge the Stoney Nakoda, Blackfoot, and Tsuu T'ina Nations as well as the provincial parks and protected areas that help steward it, particularly the Nakiska Ski Area (J. Sekerak, B. Brander, and K. Brander).

\section{Author contributions}

D.J.E. and C.G.E. conceived the ideas, D.J.E. collected and analysed the data and drafted the text, and both authors contributed substantially to revisions.

\section{References}

\author{
Alberto F, Bouffier L, Louvet JM, Lamy JB, Delzon S, Kremer A. 2011. Adaptive \\ responses for seed and leaf phenology in natural populations of sessile oak along an \\ altitudinal gradient. Journal of Evolutionary Biology 24: 1442-1454.
}

\section{Anderson JT, Inouye DW, McKinney AM, Colautti RI, Mitchell-Olds T. 2012.}

Phenotypic plasticity and adaptive evolution contribute to advancing flowering phenology in response to climate change. Proceedings of the Royal Society B: Biological Sciences 279: $3843-3852$.

This article is protected by copyright. All rights reserved. 
Austen EJ, Rowe L, Stinchcombe JR, Forrest JRK. 2017. Explaining the apparent paradox of persistent selection for early flowering. New Phytologist 215: 929-934.

Barton N. 2001. Adaptation at the edge of a species' range. In: Silvertown J, Antonovics J, eds. Integrating Ecology and Evolution in a Spatial Context. Oxford, UK: Blackwell, 365392.

Barton K. 2018. MuMIn: Multi-model inference. R package version 1.42.1. https://CRAN.R-project.org/package=MuMIn

Bates D, Maechler M, Bolker BM, Walker S. 2015. Fitting linear mixed-effects models using lme4. Journal of Statistical Software 67: 1-48.

Beniston M. 2005. Mountain climates and climatic change: An overview of processes focusing on the European Alps. Pure and Applied Geophysics 162: 1587-1606.

ter Borg SJ. 2005. Dormancy and germination of six Rhinanthus species in relation to climate. Folia Geobotanica 40: 243-260.

Bradshaw WE, Holzapfel CM. 2008. Genetic response to rapid climate change: It's seasonal timing that matters. Molecular Ecology 17: 157-166.

Bridle JR, Vines TH. 2007. Limits to evolution at range margins: when and why does adaptation fail? Trends in Ecology and Evolution 22: 140-147.

Burgess KS, Etterson JR, Galloway LF. 2007. Artificial selection shifts flowering phenology and other correlated traits in an autotetraploid herb. Heredity 99: 641-648.

Chevin LM, Lande R. 2011. Adaptation to marginal habitats by evolution of increased phenotypic plasticity. Journal of Evolutionary Biology 24: 1462-1476.

Colautti RI, Barrett SCH. 2013. Rapid adaptation to climate facilitates range expansion of an invasive plant. Science 342: 364-366.

Colautti RI, Eckert CG, Barrett SCH. 2010. Evolutionary constraints on adaptive evolution during range expansion in an invasive plant. Proceedings of the Royal Society B: Biological Sciences 277: 1799-1806.

Conover DO, Duffy TA, Hice LA. 2009. The covariance between genetic and environmental influences across ecological gradients: Reassessing the evolutionary 
significance of countergradient and cogradient variation. Annals of the New York Academy of Sciences 1168: 100-129.

Conover DO, Schultz ET. 1995. Phenotypic similarity and the evolutionary significance of countergradient variation. Trends in Ecology and Evolution 10: 248-252.

Crispo E. 2008. Modifying effects of phenotypic plasticity on interactions among natural selection, adaptation and gene flow. Journal of Evolutionary Biology 21: 1460-1469.

Diaz HF, Grosjean M, Graumlich L. 2003. Climate variability and change in high elevation regions: Past, present and future. Climatic Change 59: 1-4.

Ducarme V, Wesselingh RA. 2013. Outcrossing rates in two self-compatible, hybridising Rhinanthus species: Implications for hybrid formation. Plant Biology 15: 541-547.

Eckert C, Samis K, Lougheed S. 2008. Genetic variation across species' geographical ranges: the central-marginal hypothesis and beyond. Molecular Ecology 17: 1170-1188.

Eckhart V, Geber M, McGuire C. 2004. Experimental studies of adaptation in Clarkia xantiana. I. Sources of trait variation across a subspecies border. Evolution 58: 59-70.

Ensing DJ. 2019. Evolutionary constraints: Phenology and elevational range limits in an annual plant. PhD Thesis, Queen's University, Kingston, ON, Canada.

Estes S, Arnold SJ. 2007. Resolving the paradox of stasis: models with stabilizing selection explain evolutionary divergence on all timescales. The American Naturalist 169: 227-244.

Etterson JR. 2004. Evolutionary potential of Chamaecrista fasciculata in relation to climate change. II. Genetic architecture of three populations reciprocally planted along an environmental gradient in the great plains. Evolution 58: 1459-1471.

Forrest J, Miller-Rushing AJ. 2010. Toward a synthetic understanding of the role of phenology in ecology and evolution. Philosophical Transactions of the Royal Society B: Biological Sciences 365: 3101-3112.

Franks SJ, Sim S, Weis AE. 2007. Rapid evolution of flowering time by an annual plant in response to a climate fluctuation. Proceedings of the National Academy of Sciences of the United States of America 104: 1278-1282.

De Frenne P, Graae BJ, Rodríguez-Sánchez F, Kolb A, Chabrerie O, Decocq G, De 
Kort H, De Schrijver A, Diekmann M, Eriksson O, et al. 2013. Latitudinal gradients as natural laboratories to infer species' responses to temperature. Journal of Ecology 101: 784795.

Galloway LF, Burgess KS. 2009. Manipulation of flowering time: Phenological integration and maternal effects. Ecology 90: 2139-2148.

Ghalambor CK, McKay JK, Carroll SP, Reznick DN. 2007. Adaptive versus non-adaptive phenotypic plasticity and the potential for contemporary adaptation in new environments. Functional Ecology 21: 394-407.

Gonzalo-Turpin H, Hazard L. 2009. Local adaptation occurs along altitudinal gradient despite the existence of gene flow in the alpine plant species Festuca eskia. Journal of Ecology 97: 742-751.

Gugger S, Kesselring H, Stöcklin J, Hamann E. 2015. Lower plasticity exhibited by highversus mid-elevation species in their phenological responses to manipulated temperature and drought. Annals of Botany 116: 953-962.

Haggerty BP, Galloway LF. 2011. Response of individual components of reproductive phenology to growing season length in a monocarpic herb. Journal of Ecology 99: 242-253.

Halbritter A, Billeter R, Edwards PJ, Alexander JM. 2015. Local adaptation at range edges: comparing elevation and latitudinal gradients. Journal of Evolutionary Biology 28: 1849-1860.

Halbritter AH, Fior S, Keller I, Billeter R, Edwards PJ, Holderegger R, Karrenberg S, Pluess AR, Widmer A, Alexander JM. 2018. Trait differentiation and adaptation of plants along elevation gradients. Journal of Evolutionary Biology 31: 784-800.

Hargreaves AL, Eckert CG. 2019. Local adaptation primes cold-edge populations for range expansion but not warming-induced range shifts. Ecology Letters 22: 78-88.

Hargreaves AL, Samis KE, Eckert CG. 2014. Are species' range limits simply niche limits writ large? A review of transplant experiments beyond the range. The American Naturalist 183: $157-173$.

Hargreaves AL, Weiner JL, Eckert CG. 2015. High-elevation range limit of an annual herb is neither caused nor reinforced by declining pollinator service. Journal of Ecology 103: 
$572-584$.

Hendry AP, Day T. 2005. Population structure attributable to reproductive time: isolation by time and adaptation by time. Molecular Ecology 14: 901-916.

Holt RD, Gomulkiewicz R. 1997. How does immigration influence local adaptation? The American Naturalist 149: 563-572.

van Hulst R, Thériault A, Shipley B. 1986. The systematic position of the genus Rhinanthus (Scrophulariaceae) in North America. Canadian Journal of Botany 64: 14431449.

Inouye DW, Barr B, Armitage KB, Inouye BD. 2000. Climate change is affecting altitudinal migrants and hibernating species. Proceedings of the National Academy of Sciences of the United States of America 97: 1630-1633.

Johnson PCD. 2014. Extension of Nakagawa \& Schielzeth's $R_{\text {GLMM }}^{2}$ to random slopes models. Methods in Ecology and Evolution 5: 944-946.

Kawecki TJ, Ebert D. 2004. Conceptual issues in local adaptation. Ecology Letters 7: 12251241

Keller F, Körner C. 2003. The role of photoperiodism in alpine plant development. Artic, Antarctic, and Alpine Research 35: 361-368.

Kirkpatrick M, Barton N. 1997. Evolution of a species' range. The American Naturalist 150: $1-23$.

Kooyers NJ, Greenlee AB, Colicchio JM, Oh M, Blackman BK. 2015. Replicate altitudinal clines reveal that evolutionary flexibility underlies adaptation to drought stress in annual Mimulus guttatus. New Phytologist 206: 152-165.

Körner C. 1999. Alpine plant life: functional ecology of high mountain ecosystems. Berlin, Germany: Springer-Verlag.

Körner C. 2007. The use of 'altitude' in ecological research. Trends in Ecology and Evolution 22: 569-574.

De Kort H, Vander Mijnsbrugge K, Vandepitte K, Mergeay J, Ovaskainen O, Honnay O. 2016. Evolution, plasticity and evolving plasticity of phenology in the tree species Alnus

This article is protected by copyright. All rights reserved. 
glutinosa. Journal of Evolutionary Biology 29: 253-264.

Kremer A, Potts BM, Delzon S. 2014. Genetic divergence in forest trees: Understanding the consequences of climate change. Functional Ecology 28: 22-36.

\section{Lázaro-Nogal A, Matesanz S, Godoy A, Pérez-Trautman F, Gianoli E, Valladares F.}

2015. Environmental heterogeneity leads to higher plasticity in dry-edge populations of a semi-arid Chilean shrub: Insights into climate change responses. Journal of Ecology 103: $338-350$.

Legendre P. 2018. lmodel2: Model II regression. R package version 1.7-3. https://CRAN.Rproject.org/package $=$ lmodel 2

Levin DA. 2009. Flowering-time plasticity facilitates niche shifts in adjacent populations. New Phytologist 183: 661-666.

Vander Mijnsbrugge K, Turcsán A, Michiels B. 2016. Population differentiation and phenotypic plasticity in temperature response of bud burst in Frangula alnus provenances of different latitude. Plant Systematics and Evolution 302: 257-264.

Miller-Rushing AJ, Høye TT, Inouye DW, Post E. 2010. The effects of phenological mismatches on demography. Philosophical Transactions of the Royal Society of London. Series B, Biological Sciences 365: 3177-3186.

Miller P, Lanier W, Brandt S. 2001. Using growing degree days to predict plant stages. Montana State University Extension Service 9: MT00103AG.

Montague J, Barrett S, Eckert C. 2008. Re-establishment of clinal variation in flowering time among introduced populations of purple loosestrife (Lythrum salicaria, Lythraceae). Journal of Evolutionary Biology 21: 234-245.

Munguía-Rosas MA, Ollerton J, Parra-Tabla V, De-Nova JA. 2011. Meta-analysis of phenotypic selection on flowering phenology suggests that early flowering plants are favoured. Ecology Letters 14: 511-521.

Münzbergová Z, Hadincová V, Skálová H, Vandvik V. 2017. Genetic differentiation and plasticity interact along temperature and precipitation gradients to determine plant performance under climate change. Journal of Ecology 105: 1358-1373.

This article is protected by copyright. All rights reserved. 
Nagy L, Grabherr G. 2009. The biology of alpine habitats. Oxford, UK: Oxford University Press.

Nakagawa S, Schielzeth H. 2013. A general and simple method for obtaining $R^{2}$ from generalized linear mixed-effects models. Methods in Ecology and Evolution 4: 133-142.

Nogués-Bravo D, Araújo MB, Errea MP, Martínez-Rica JP. 2007. Exposure of global mountain systems to climate warming during the 21st Century. Global Environmental Change 17: 420-428.

Olsson K, Ågren J. 2002. Latitudinal population differentiation in phenology, life history and flower morphology in the perennial herb Lythrum salicaria. Journal of Evolutionary Biology 15: 983-996.

Parmesan C. 2006. Ecological and evolutionary responses to recent climate change. Annual Review of Ecology, Evolution, and Systematics 37: 637-669.

Parmesan C, Yohe G. 2003. A globally coherent fingerprint of climate change impacts across natural systems. Nature 421: 37-42.

Pfennigwerth AA, Bailey JK, Schweitzer JA. 2017. Trait variation along elevation gradients in a dominant woody shrub is population-specific and driven by plasticity. $A o B$ PLANTS 9: plx027.

Pigliucci M. 2001. Phenotypic plasticity: beyond nature and nurture. Baltimore, MD, USA: Johns Hopkins University Press.

Polechová J, Barton NH. 2015. Limits to adaptation along environmental gradients. Proceedings of the National Academy of Sciences 112: 6401-6406.

Roff DA. 2002. Life History Evolution. Sunderland, MA, USA: Sinauer Associates, Inc. Sagarin RD, Gaines SD, Gaylord B. 2006. Moving beyond assumptions to understand abundance distributions across the ranges of species. Trends in Ecology and Evolution 21: $524-530$.

\section{Sedlacek J, Cortés AJ, Wheeler J, Bossdorf O, Hoch G, Klápště J, Lexer C, Rixen C,} Wipf S, Karrenberg S, et al. 2016. Evolutionary potential in the Alpine: trait heritabilities and performance variation of the dwarf willow Salix herbacea from different elevations and 
microhabitats. Ecology and Evolution 6: 3940-3952.

Sexton JP, Hufford MB, Bateman AC, Lowry DB, Meimberg H, Strauss SY, Rice KJ. 2016. Climate structures genetic variation across a species' elevation range: A test of range limits hypotheses. Molecular Ecology 25: 911-928.

Sexton JP, Strauss SY, Rice KJ. 2011. Gene flow increases fitness at the warm edge of a species' range. Proceedings of the National Academy of Sciences of the United States of America 108: 11704-11709.

La Sorte FA, Butchart SHM, Jetz W, Böhning-Gaese K. 2014. Range-wide latitudinal and elevational temperature gradients for the world's terrestrial birds: Implications under global climate change. PLoS ONE 9: e98361.

La Sorte FA, Jetz W. 2010. Projected range contractions of montane biodiversity under global warming. Proceedings of the Royal Society B: Biological Sciences 277: 3401-3410.

Soularue J-P, Kremer A. 2012. Assortative mating and gene flow generate clinal phenological variation in trees. BMC Evolutionary Biology 12: 79.

Soularue J-P, Kremer A. 2014. Evolutionary responses of tree phenology to the combined effects of assortative mating, gene flow and divergent selection. Heredity 113: 485-494.

\section{Toftegaard T, Posledovich D, Navarro-Cano JA, Wiklund C, Gotthard K, Ehrlén J.} 2016. Variation in plant thermal reaction norms along a latitudinal gradient - more than adaptation to season length. Oikos: 622-628.

Uller T, Nakagawa S, English S. 2013. Weak evidence for anticipatory parental effects in plants and animals. Journal of Evolutionary Biology 26: 2161-2170.

Vitasse Y, Delzon S, Bresson CC, Michalet R, Kremer A. 2009a. Altitudinal differentiation in growth and phenology among populations of temperate-zone tree species growing in a common garden. Canadian Journal of Forest Research 39: 1259-1269.

\section{Vitasse Y, Delzon S, Dufrêne E, Pontailler JY, Louvet JM, Kremer A, Michalet R.}

2009b. Leaf phenology sensitivity to temperature in European trees: Do within-species populations exhibit similar responses? Agricultural and Forest Meteorology 149: 735-744.

Wadgymar SM, Cumming MN, Weis AE. 2015. The success of assisted colonization and 
assisted gene flow depends on phenology. Global Change Biology 21: 3786-3799.

Wadgymar SM, Daws SC, Anderson JT. 2017. Integrating viability and fecundity selection to illuminate the adaptive nature of genetic clines. Evolution Letters 1: 26-39.

Wadgymar SM, Mactavish RM, Anderson JT. 2018a. Transgenerational and withingeneration plasticity in response to climate change: Insights from a manipulative field experiment across an elevational gradient. The American Naturalist 192: 698-714.

Wadgymar SM, Ogilvie JE, Inouye DW, Weis AE, Anderson JT. 2018b. Phenological responses to multiple environmental drivers under climate change: insights from a long-term observational study and a manipulative field experiment. New Phytologist 218: 517-529.

Weis AE. 2015. On the potential strength and consequences for nonrandom gene flow caused by local adaptation in flowering time. Journal of Evolutionary Biology 28: 699-714.

Weis AE, Kossler TM. 2004. Genetic variation in flowering time induces phenological assortative mating: Quantitative genetic methods applied to Brassica rapa. American Journal of Botany 91: 825-836.

Westbury DB. 2004. Rhinanthus minor L. Journal of Ecology 92: 906-927.

Whittet R, Cavers S, Cottrell J, Rosique-Esplugas C, Ennos R. 2017. Substantial variation in the timing of pollen production reduces reproductive synchrony between distant populations of Pinus sylvestris L. in Scotland. Ecology and Evolution 7: 5754-5765.

Yamagishi H, Allison TD, Ohara M. 2005. Effect of snowmelt timing on the genetic structure of an Erythronium grandiflorum population in an alpine environment. Ecological Research 20: 199-204.

\section{Supporting information}

The following Supporting Information is available for this article:

Notes S1 - Site characteristics and transplant experimental design

Notes S2 - Temperature logger deployment and $T_{\mathrm{BASE}}$ sensitivity analyses

Notes S3 - Estimation of Spring 2014 temperatures

Notes S4 - Trait weighting, size estimation and estimation of growing season length

This article is protected by copyright. All rights reserved. 
Notes S5 - Survival of natural and transplanted individuals

Notes S6 - Emergence, emergence to first flower, first slower to first mature fruit and first mature fruit predicted by source season length and destination season length

Notes S7 - Results of core analyses using days instead of GDD

\section{Figure captions}

Fig. 1. Patterns and sources of phenotypic variation in phenology for a species distributed along a gradient of season length. Panel (a) represents the observed cline in natural populations where season length and phenology correlate positively. Panels (b) and (c) demonstrate different plastic trait clines in response to transplantation among sites in a reciprocal transplant experiment (RTE). Panels (d-f) display potential responses of a trait to transplantation across a range of environments along which the trait naturally varies. Trait shift (y-axis) is the difference between the trait value of a source populations at its home site and the trait value at a destination site that it has been transplanted to. Trait distance ( $\mathrm{x}$-axis) is the difference in trait value between the source at home and the local phenotype at the destination site. Using flowering time of a low elevation, long season source planted in a high elevation, short season destination as an example, trait shift is the difference between flowering time when planted at home (low elevation site) and when planted away (high elevation site). Trait distance then is the difference in the local phenotype (e.g. flowering time) between the low and high elevation sites. In (b), transplanted individuals exhibit cogradient plasticity and match the destination phenotype. Our hypothetical example point would lie in the lower left quadrant (short time to flowering at high elevation - long time to flowering at low); the reciprocal transplant would lie in the upper right. If the trait is governed solely by genetic differentiation (e) we expect no trait shift response to trait distance. Counter-gradient plasticity occurs when traits in transplanted individuals move away from the local phenotype at the destination site, and thus trait shift and trait distance correlate negatively.

Fig. 2. When fitness declines along a gradient of declining season length (solid line), selection should favour increased plasticity towards the range limit (dashed line at fitness where $\boldsymbol{\lambda}=1$ ) even when interannual variation in season length (dashed lines in grey squares) is the same across the range. This is because the fitness change per unit change in season 
length (vertical dimension of the shaded rectangles) increases towards the range margin, hence the benefits of plasticity are higher. If season length variation increases towards the upper limit, this will further increase the advantage of plasticity in these populations as fitness variation of static genotypes would correspondingly increase.

Fig. 3. All three measures of growing season length $(\mathbf{a}-\mathbf{c})$ decline with increasing elevation among 12 study sites in the Canadian Rocky Mountains, but there is considerable variation among sites at similar elevations and among years within sites (significant effect of year, lines in all panels; Table S4.1 in Supporting Information Notes S4). Marginal $R^{2}$ values from a model including fixed effects of elevation $(\mathrm{E})$ and year $(\mathrm{Y})$ are in the top right of each panel. Conditional $R^{2}$ values which include the random effect of site were $0.95,0.95$, and 0.87 from top to bottom, respectively.

Fig. 4. Clines in five phenological traits (a-e) across a gradient of growing season length among 12 populations of Rhinanthus minor in the Canadian Rocky Mountains (Table 1). Marginal $R^{2}$ values from models including the fixed effects of season length (S), year (Y), and the interaction between season length and year $(\mathrm{S} \times \mathrm{Y})$ are in the top right of each panel, with significant fixed effects indicated by letters. Conditional $R^{2}$ values, which include the random effects of site and plot nested within site, were $0.84,0.56,0.75,0.55$, and 0.90 from left to right and top to bottom respectively. Note that the $\mathrm{x}$-axis is inverted to mirror declining season length with increasing elevation.

Fig. 5. Differentiation in growing degree days (GDD) to first flower among populations of Rhinanthus minor when grown in common planting sites along an elevational gradient of season length. Each panel (a-i) is a different transplant destination site with site identifier and season length as panel headings. GDD to first flower declines with the average source population growing season length $\left(\mathrm{S}_{\mathrm{P}}\right.$, Table 2$)$. Annual GDDs at each source site (x-axis) are three-year averages (2014-2016). Note that the $\mathrm{x}$-axis is reversed to represent the decline in growing season length with increasing elevation. Results are similar for the other four phenological traits, though significant clines are less common (Supporting Information Notes S6).

This article is protected by copyright. All rights reserved. 
Fig. 6. Strong co-gradient plasticity for flowering time among populations of Rhinanthus minor across an elevational gradient of growing season length (See also Table 3). Each panel (a-j) is a single source population planted at seven transplant sites in 2015 and nine in 2016. Hence the clines represent their plastic response to variation in growing season length at the destination site $\left(\mathrm{S}_{\mathrm{D}}\right)$ in the year of study. Note that the $\mathrm{x}$-axis is reversed to represent the decline in growing season length with increasing elevation. Source population code and mean season length of that source $\left(S_{\mathrm{P}}\right)$ are in the panel headers. Results are similar for the other phenological traits (Supporting Information Notes S6). Note that T3-High (i) was a source for 2015 only, and was replaced by T3-Marmot high (j) for the 2016 transplant experiment (see the Materials and Methods section and Notes S1 for detail).

Fig. 7. Strong co-gradient plasticity: genotypes from nine Rhinanthus minor populations reciprocally transplanted along an elevational gradient of season length nearly match resident phenological phenotypes of each trait (a-e) at each site. Each point is a combination of year and source population planted at a non-home site. Slopes of the major axis Model II regression lines $(m$, all $P<0.001)$ are in the upper left corner of each panel with confidence limits estimated via permutation in parentheses. Full co-gradient plastic response would lie on the dotted $1: 1$ line $(m=1)$, while genetic differentiation without a plastic response is indicated by points along the horizontal dotted line at phenological shift $=0(m=0)$.

Fig. 8. Change in the phenotypes of five phenological traits (a-e) of Rhinanthus minor in response to inter-annual variation in growing season length. Data are from 12 natural populations studied in three consecutive years. Points are between-year, pairwise comparisons of each population. The $\mathrm{x}$-axis is the difference in annual growing degree days (AnGDD) between years, and the y-axis is the between-year difference in growing degree days (GDD) required to reach the focal life history event. The dotted 1:1 line shows where a change in season length is matched by an equal change in the GDD to the life history event. Slopes of the major axis Model II regression lines $(m)$ are in the upper left corner of each panel with confidence limits estimated via permutation in parentheses. 
Table 1. Phenology of naturally occurring Rhinanthus minor from 13 sites across an elevational gradient of season length in the Canadian Rockies is predicted by annual growing degree days (S) and year (Y; Fig. 4).

\begin{tabular}{|c|c|c|c|c|c|c|}
\hline \multicolumn{3}{|c|}{ Fixed } & \multicolumn{4}{|c|}{ Akaike } \\
\hline Trait & effects & Standardised slopes ${ }^{*}$ & Decline $(\%)^{* *}$ & $\Delta \mathrm{AICc}$ & weight & Marginal $R^{2}$ \\
\hline AnGDD to emergence & $\mathrm{S} \times \mathrm{Y}$ & $0.65,1.14,1.11$ & $26.1,61.5,68.1$ & 4.75 & 0.91 & 0.64 \\
\hline Emergence to first flower & $S+Y$ & 0.55 & $34.7,38.3,42.9$ & 10.41 & 0.99 & 0.31 \\
\hline AnGDD to first flower & $\mathrm{S} \times \mathrm{Y}$ & $0.37,0.80,0.81$ & $31.9,45.2,52.4$ & 42.42 & 1.00 & 0.54 \\
\hline First flower to first mature fruit & $\mathrm{S} \times \mathrm{Y}$ & $0.94,0.67,0.64$ & $38.3,27.9,24.7$ & 17.67 & 1.00 & 0.41 \\
\hline AnGDD to first mature fruit & $\mathrm{S} \times \mathrm{Y}$ & $0.87,1.08,1.08$ & $30.3,43.9,50.0$ & 41.05 & 1.00 & 0.79 \\
\hline
\end{tabular}

*Slopes are the effect of season length on the trait and are given in order of year when interactions are present (2014 - 2016).

** Decline is the percent change from the longest to the shortest growing season in each year $(2014-2016)$ as estimated by the regression lines (Fig. 4).

This article is protected by copyright. All rights reserved. 
Table 2. Analysis of covariation of phenological traits and mean growing season length experienced by source populations $\left(\mathrm{S}_{\mathrm{P}}\right)$ among montane populations of Rhinanthus minor planted at nine destination sites (D) indicates low to moderate clinal differentiation in phenology among source populations (Fig. 5). na, not applicable.

\begin{tabular}{llrrrrr}
\hline Year & Trait & Fixed & Standardised & \multicolumn{3}{c}{ Akaike } \\
\hline 2015 & AnGDD to emergence & effects & slope & $\Delta$ AICc & weight & $R^{2}$ \\
& Emergence to first flower & D & na & 2.18 & 0.75 & 0.96 \\
& AnGDD to first flower & $\mathrm{S}_{\mathrm{P}}+\mathrm{D}$ & 0.30 & 12.26 & 1.00 & 0.69 \\
& First flower to first mature fruit & $\mathrm{S}+\mathrm{D}$ & 0.26 & 17.64 & 1.00 & 0.83 \\
& AnGDD to first mature fruit & $\mathrm{S}_{\mathrm{P}}+\mathrm{D}$ & 0.093 & 1.74 & 0.71 & 0.88 \\
\hline 2016 & AnGDD to emergence & $\mathrm{S}_{\mathrm{P}}+\mathrm{D}$ & 0.066 & 7.81 & 0.98 & 0.97 \\
& Emergence to first flower & $\mathrm{S}_{\mathrm{P}}+\mathrm{D}$ & 0.26 & 16.91 & 1.00 & 0.87 \\
& AnGDD to first flower & $\mathrm{S}_{\mathrm{P}}+\mathrm{D}$ & 0.18 & 12.52 & 1.00 & 0.96 \\
& First flower to first mature fruit & $\mathrm{S}_{\mathrm{P}}+\mathrm{D}$ & -0.11 & 3.46 & 0.86 & 0.86 \\
& AnGDD to first mature fruit & $\mathrm{S}_{\mathrm{P}}+\mathrm{D}$ & 0.13 & 13.56 & 1.00 & 0.95 \\
\hline
\end{tabular}

This article is protected by copyright. All rights reserved. 
Table 3. Plastic covariation between phenological traits and growing season length at destination planting sites $\left(\mathrm{S}_{\mathrm{D}}\right)$ across an elevational gradient of season length for nine source populations (P) populations of Rhinanthus minor in the Canadian Rocky Mountains (Fig. 6).

\begin{tabular}{llrrrrr}
\hline \multirow{2}{*}{ Year } & Trait & $\begin{array}{c}\text { Fixed } \\
\text { effects }\end{array}$ & $\begin{array}{r}\text { Standardised } \\
\text { slope }\end{array}$ & \multicolumn{3}{c}{ Akaike } \\
\hline 2015 & AnGDD to emergence & $\mathrm{S}_{\mathrm{D}}$ & 0.77 & 16.01 & 1.00 & 0.58 \\
& Emergence to first flower & $\mathrm{S}_{\mathrm{D}}+\mathrm{P}$ & 0.65 & 16.57 & 1.00 & 0.70 \\
& AnGDD to first flower & $\mathrm{S}_{\mathrm{D}}+\mathrm{P}$ & 0.69 & 2.56 & 0.78 & 0.63 \\
& First flower to first mature fruit & $\mathrm{S}_{\mathrm{D}}+\mathrm{P}$ & 0.76 & 19.84 & 1.00 & 0.57 \\
& AnGDD to first mature fruit & $\mathrm{S}_{\mathrm{D}}$ & 0.93 & 9.70 & 0.99 & 0.86 \\
\hline 2016 & AnGDD to emergence & $\mathrm{S}_{\mathrm{D}}$ & 0.82 & 16.58 & 1.00 & 0.67 \\
& Emergence to first flower & $\mathrm{S}_{\mathrm{D}}+\mathrm{P}$ & 0.88 & 19.68 & 1.00 & 0.88 \\
& AnGDD to first flower & $\mathrm{S}_{\mathrm{D}}+\mathrm{P}$ & 0.88 & 0.05 & 0.51 & 0.81 \\
& First flower to first mature fruit & $\mathrm{S}_{\mathrm{D}}$ & 0.72 & 16.77 & 1.00 & 0.51 \\
& AnGDD to first mature fruit & $\mathrm{S}_{\mathrm{D}}$ & 0.92 & 4.42 & 0.90 & 0.84
\end{tabular}

*All top models included $\mathrm{S}_{\mathrm{D}}$ indicating significant plasticity.

*** Positive slopes indicate co-gradient plasticity.

This article is protected by copyright. All rights reserved. 
Table 4. A summary of studies documenting counter $(\mathrm{CnGV})$ or co-gradient $(\mathrm{CoGV})$ patterns of plant phenology.

\begin{tabular}{|c|c|c|c|c|c|c|}
\hline Citation & Species & Gradient & Experiment type & Traits & Pattern & Currency \\
\hline \multirow{4}{*}{$\begin{array}{l}\text { Eckhart et al. } \\
\text { (2004) }\end{array}$} & Clarkia & Elevation & 3 common & First flower & CnGV (space) & Date of \\
\hline & xantiana & & $\begin{array}{l}\text { gardens across } \\
\text { gradient }\end{array}$ & & CoGV (time) & \\
\hline & Clarkia & Elevation & 3 common & Flower & CnGV (overall) & Days to \\
\hline & xantiana & & $\begin{array}{l}\text { gardens across } \\
\text { gradient }\end{array}$ & $\begin{array}{l}\text { development } \\
\text { time }\end{array}$ & CoGV (wet year) & \\
\hline \multirow{3}{*}{$\begin{array}{l}\text { Vitasse et al. } \\
(2009 \mathrm{~b}, \mathrm{a})^{* *} \text {; } \\
\text { Kremer } \text { et al. } \\
(2014)\end{array}$} & $\begin{array}{l}\text { Quercus } \\
\text { petraea }\end{array}$ & Elevation & Common garden & Leaf out & $\mathrm{CoGV}$ & Date of \\
\hline & $\begin{array}{l}\text { Quercus } \\
\text { petraea }\end{array}$ & Elevation & Common garden & $\begin{array}{l}\text { Leaf } \\
\text { senescence }\end{array}$ & $\mathrm{CnGV}$ & Date of \\
\hline & $\begin{array}{l}\text { Fagus } \\
\text { sylvatica }\end{array}$ & Elevation & Common garden & Leaf out & $\mathrm{CnGV}$ & Date of \\
\hline $\begin{array}{l}\text { De Kort et al. } \\
\text { (2016) }\end{array}$ & $\begin{array}{l}\text { Alnus } \\
\text { glutinosa }\end{array}$ & Latitude & Common garden & Bud burst & $\mathrm{CnGV}$ & Date of \\
\hline Vander & Frangula & Latitude & Common garden & Bud burst & $\mathrm{CnGV}$ & Date of \\
\hline $\begin{array}{l}\text { Mijnsbrugge et al. } \\
\text { (2016) }\end{array}$ & alnus & & & & & \\
\hline \multirow[t]{6}{*}{$\begin{array}{l}\text { Toftegaard et al. } \\
\text { (2016) }\end{array}$} & $\begin{array}{l}\text { Arabidopsis } \\
\text { thaliana }\end{array}$ & Latitude & Common garden & First flower & $\mathrm{CoGV}$ & Days to \\
\hline & Arabis glabra & Latitude & Common garden & First flower & $\mathrm{CnGV}$ & Days to \\
\hline & Arabis hirsuta & Latitude & Common garden & First flower & $\mathrm{CoGV}$ & Days to \\
\hline & Capsella & Latitude & Common garden & First flower & CnGV (south population) & Days to \\
\hline & bursa-pastoris & & & & $\begin{array}{l}\text { CoGV (Mid and North } \\
\text { populations) }\end{array}$ & \\
\hline & $\begin{array}{l}\text { Cardamine } \\
\text { pratensis }\end{array}$ & Latitude & Common garden & First flower & CoGV & Days to \\
\hline Whittet et al. & Pinus & Elevation & Common garden & Pollen release & $\mathrm{CnGV}$ & Days to \\
\hline
\end{tabular}

This article is protected by copyright. All rights reserved. 
Wadgymar et al. Boechera

"Papers were identified with an ISI Web of Science search for “co-gradient” OR “counter-gradient" OR "co-gradient" OR "counter-gradient" AND "plasticity." This search yielded 153 studies, of which just 14 were primary research on one or a few plant species and only 7 of these studied phenological traits (searched 25 January 2019). Here we summarise these studies (organized by date) documenting counter (CnGV) or co-gradient (CoGV) patterns of plant phenology finding that none use GDDs as a currency of phenology to describe the direction of response. We include an $8^{\text {th }}$ study (Wadgymar et al., 2017) identified during review.

** Kremer et al. (2014) integrate the separate natural cline and common garden studies of (Vitasse et al., 2009a,b).

**** De Kort et al. (2016, p. 259) find that of four source regions, the warmest has the earliest phenology across warm and cold treatments. The three other source regions (France, Belgium, and Denmark) were indistinguishable in the cold treatment, but the coldest (Denmark) was fastest in the warm. They call the pattern CnGV because the start date is later in the North, but earlier in the common garden. Instead, a CoGV pattern might be expected using GDD to, rather than dates (see also Toftegaard et al., 2016; Vander Mijnsbrugge et al., 2016)

This article is protected by copyright. All rights reserved. 
(a) Phenotypic cline

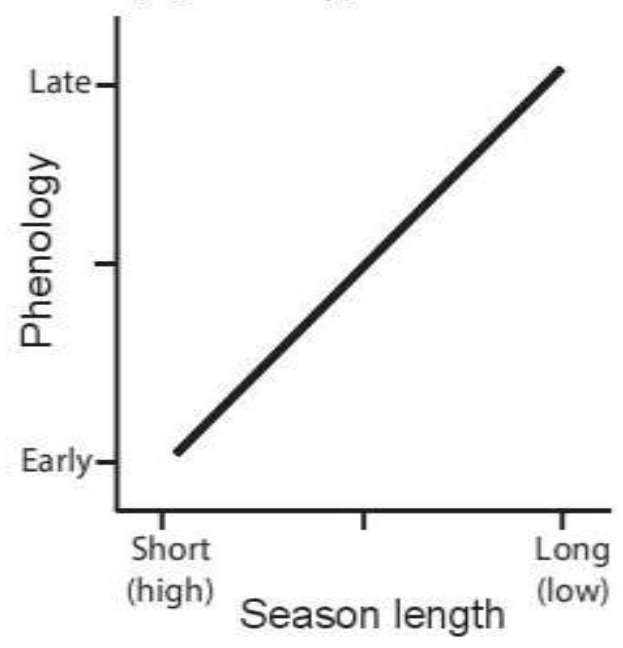

(d) Co-gradient plasticity (b) Co-gradient plasticity

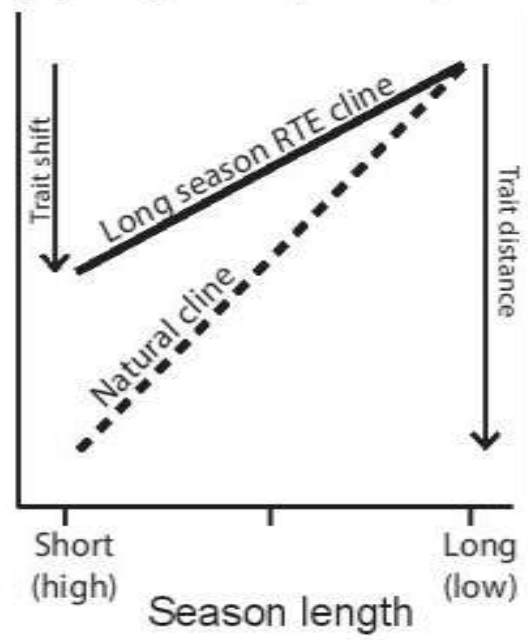

(e) Genetic differentiation (c) Counter-gradient plasticity

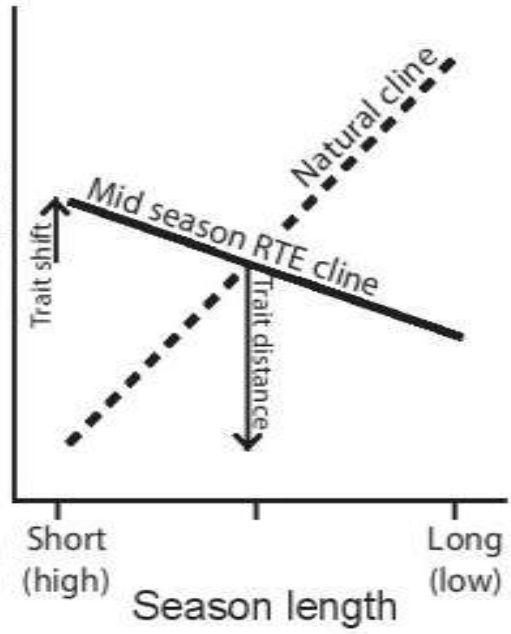

(f) Counter-gradient plasticity

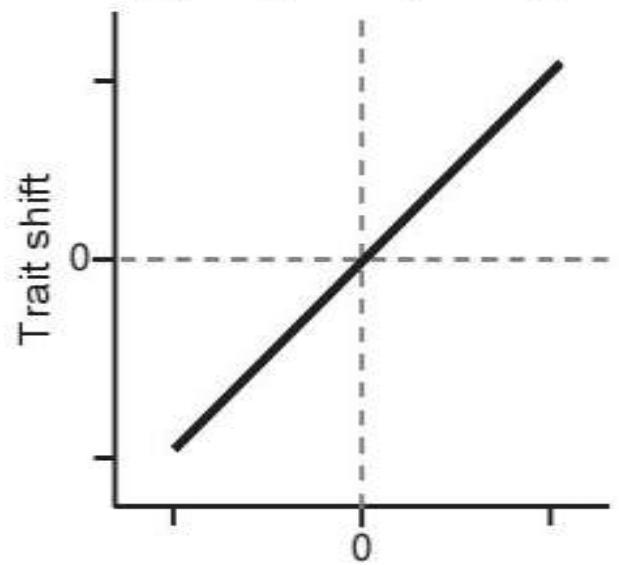

Trait distance

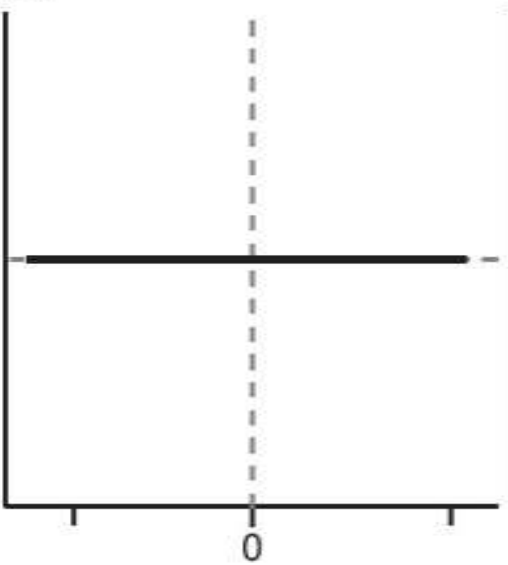

Trait distance

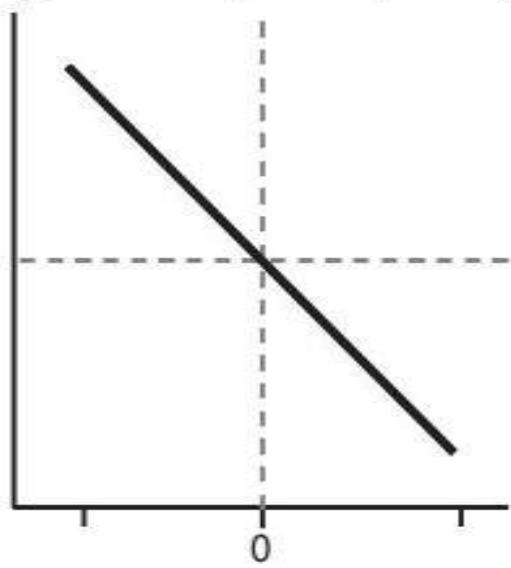

Trait distance

This article is protected by copyright. All rights reserved. 


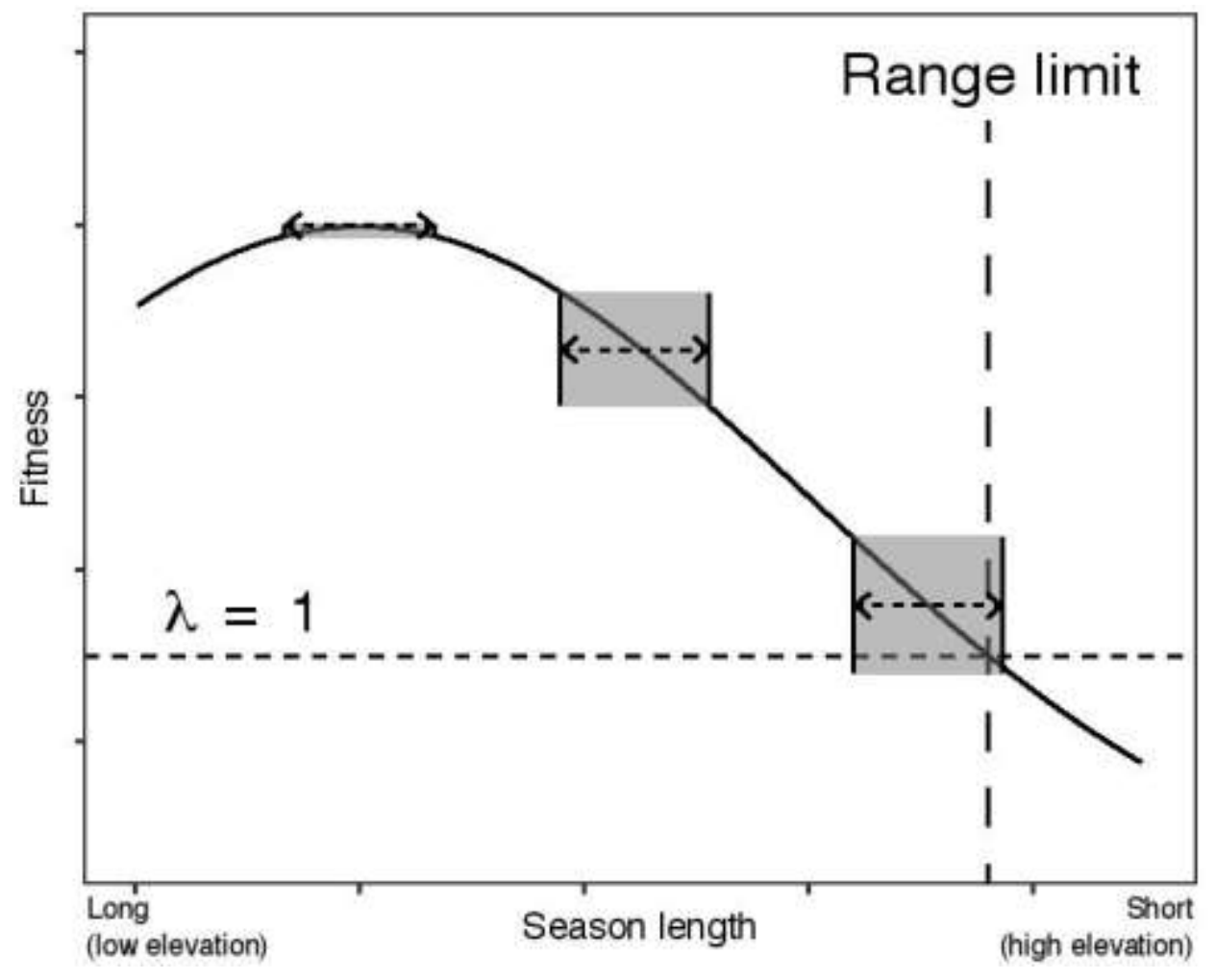

This article is protected by copyright. All rights reserved. 
$\Delta \cdot 2014 \theta 2015-\mathbb{2} 2016$
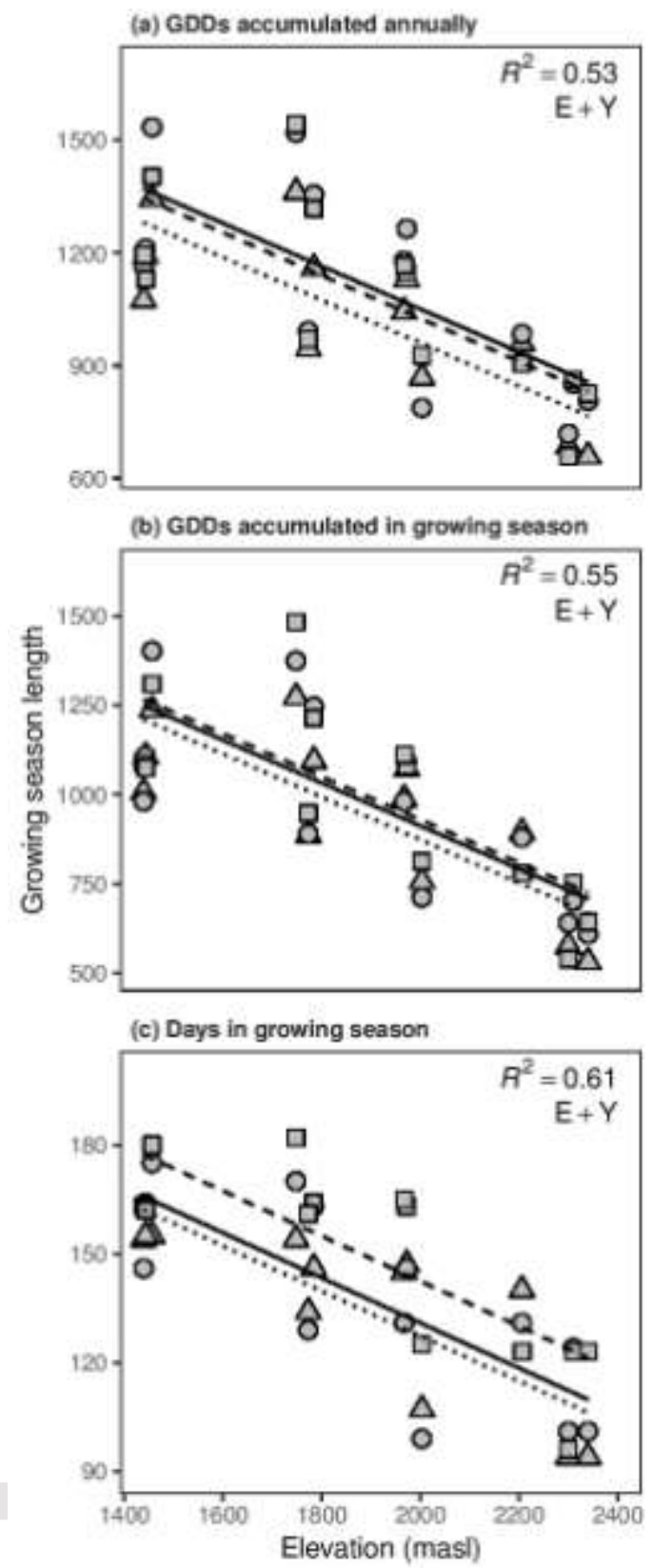

This article is protected by copyright. All rights reserved. 
(a) AnGDD to emergence

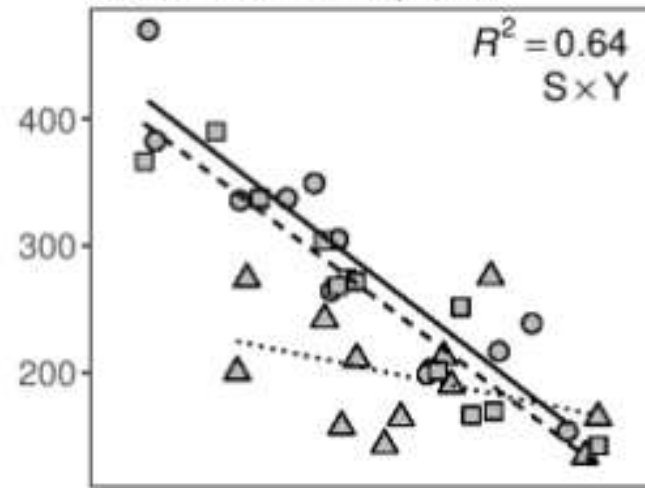

(c) AnGDD to first flower

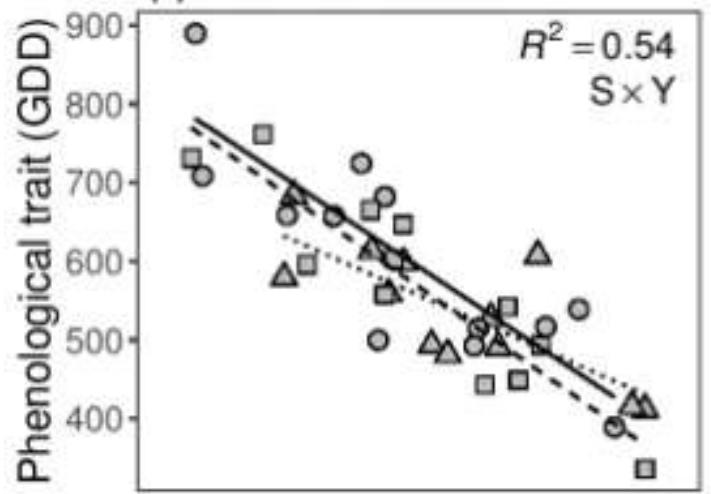

(e) AnGDD to first mature fruit

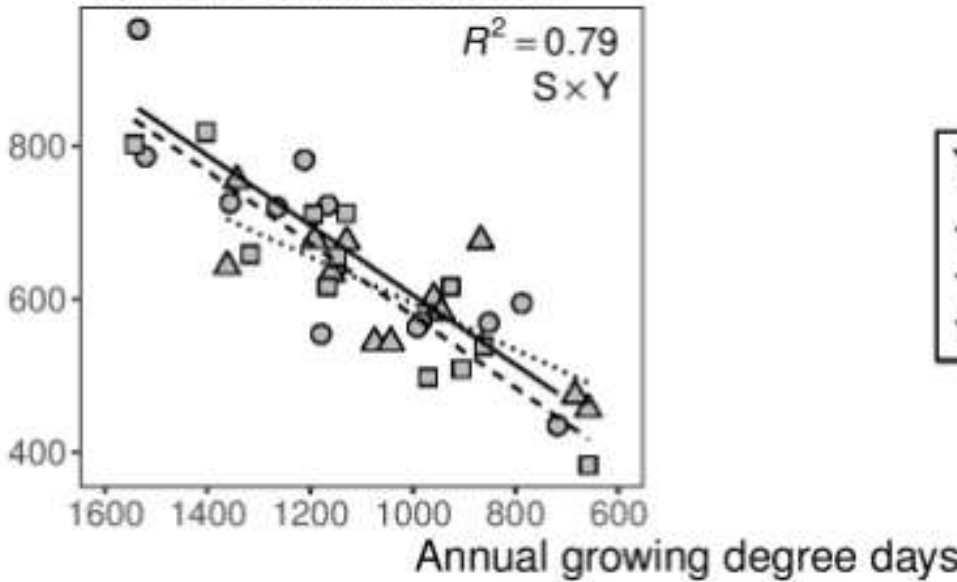

(b) Emergence to first flower

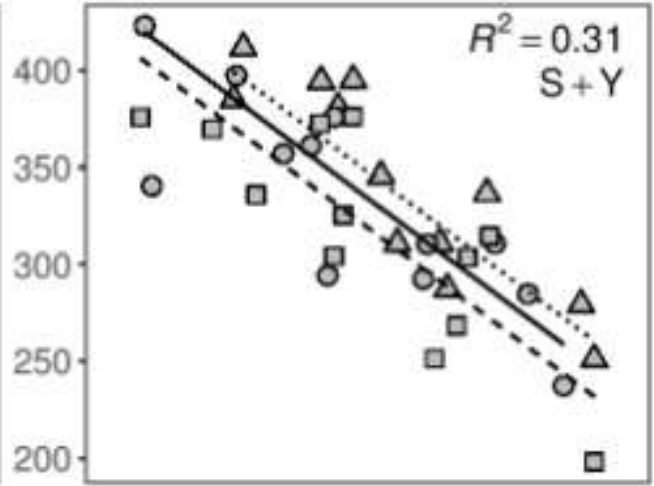

(d) First flower to first mature fruit

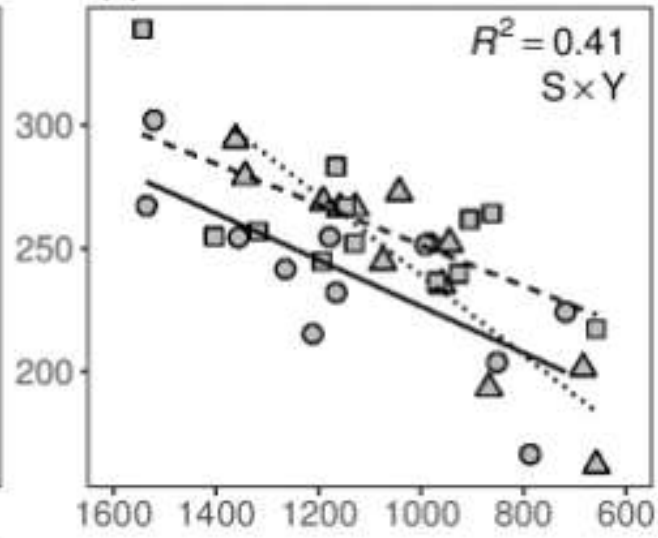

Year

$\triangle 2014$

- 2015

나 2016

This article is protected by copyright. All rights reserved. 
Differentiation among source populations

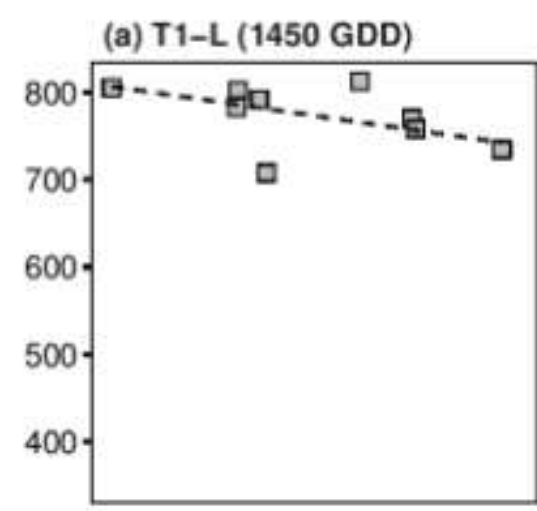

(b) T1-MH (1199 GDD)

(c) T1-H (940 GDD)

(d) T2-L (1166 GDD)

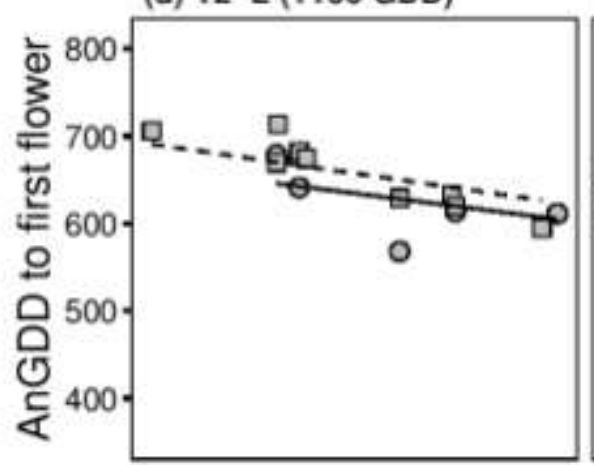

(e) T2-MH (1172 GDD)
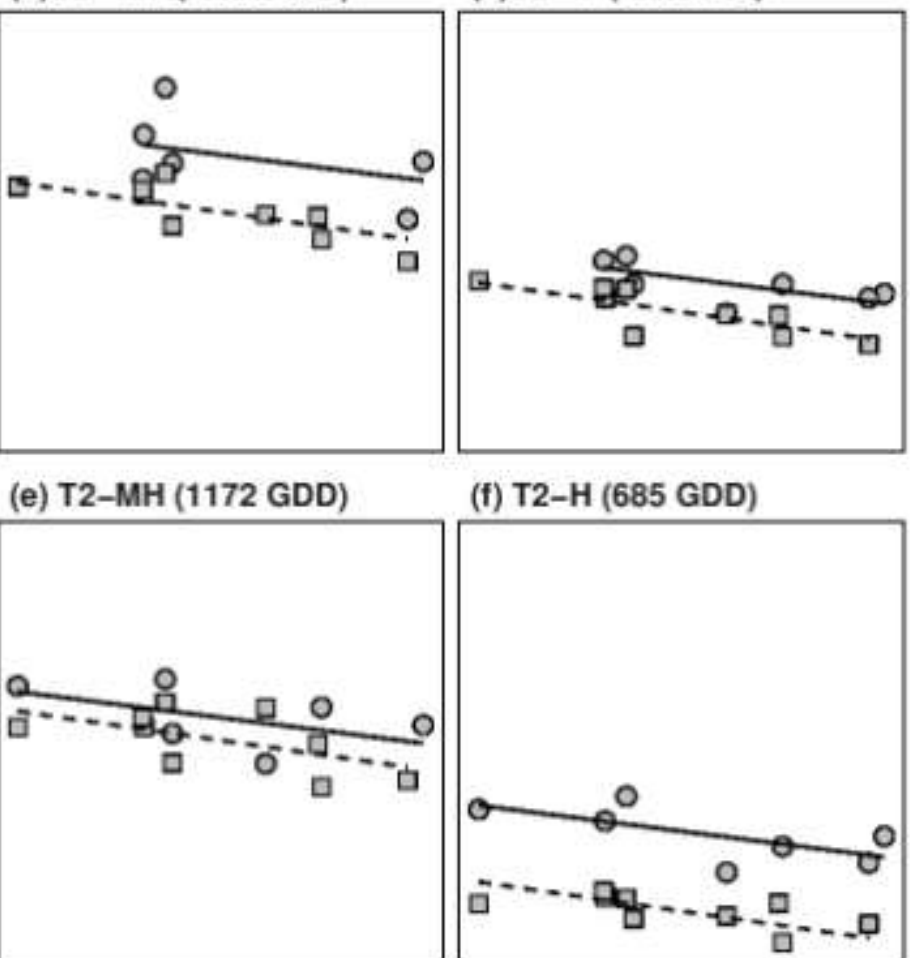

(f) T2-H (685 GDD)

(g) T3-L (1181 GDD)

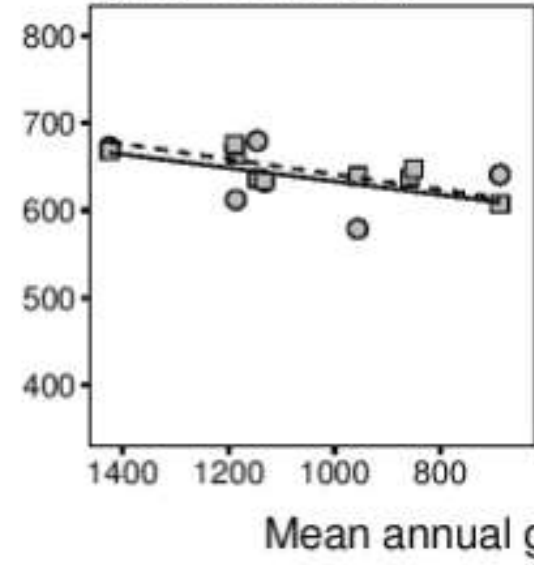

(h) T3-MH (866 GDD)
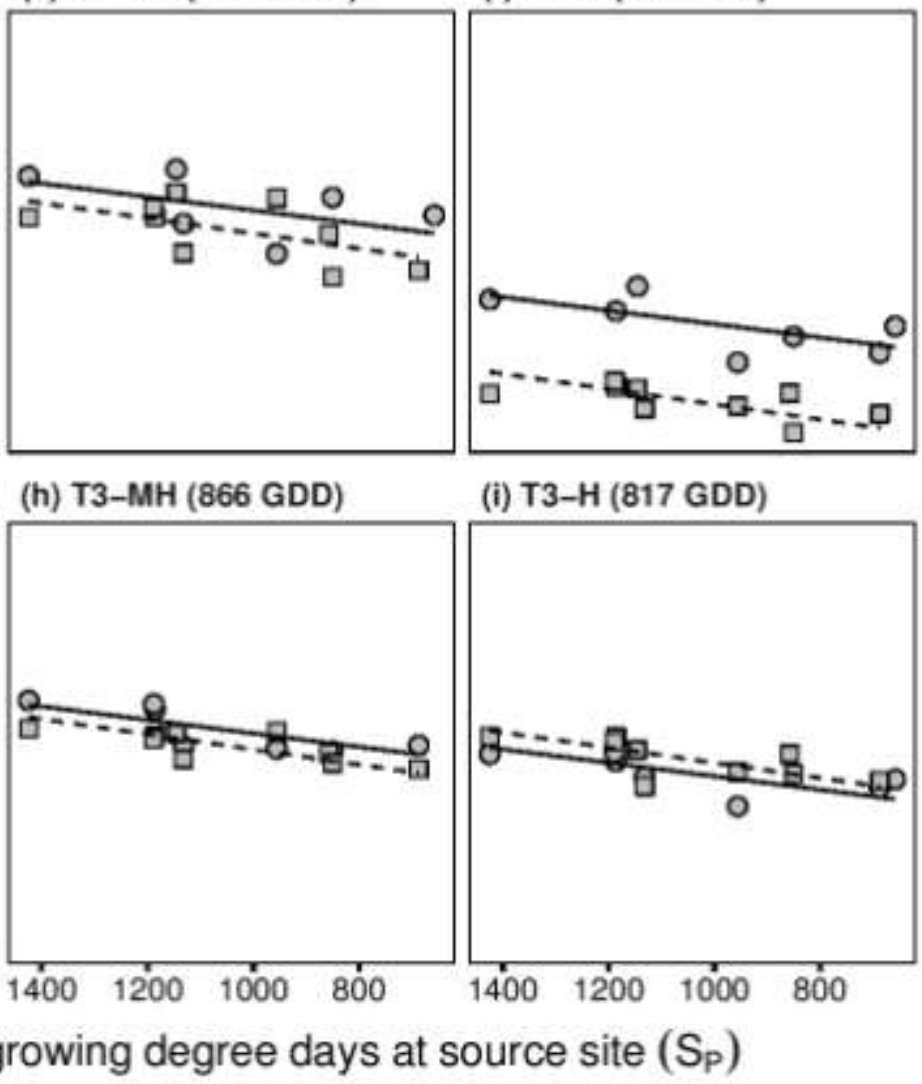

This article is protected by copyright. All rights reserved. 

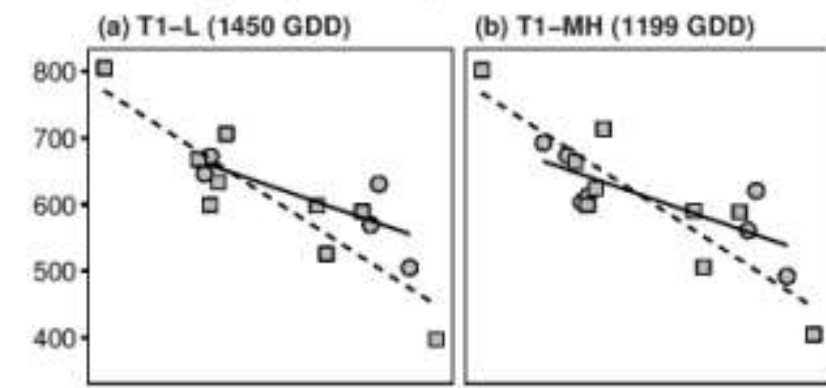

(c) T1-H (940 GDD)

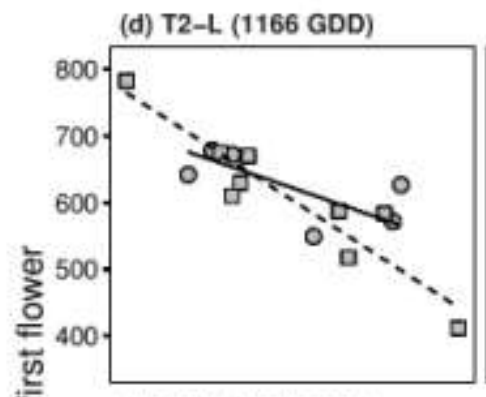

(e) T2-MH (1172 GDD)
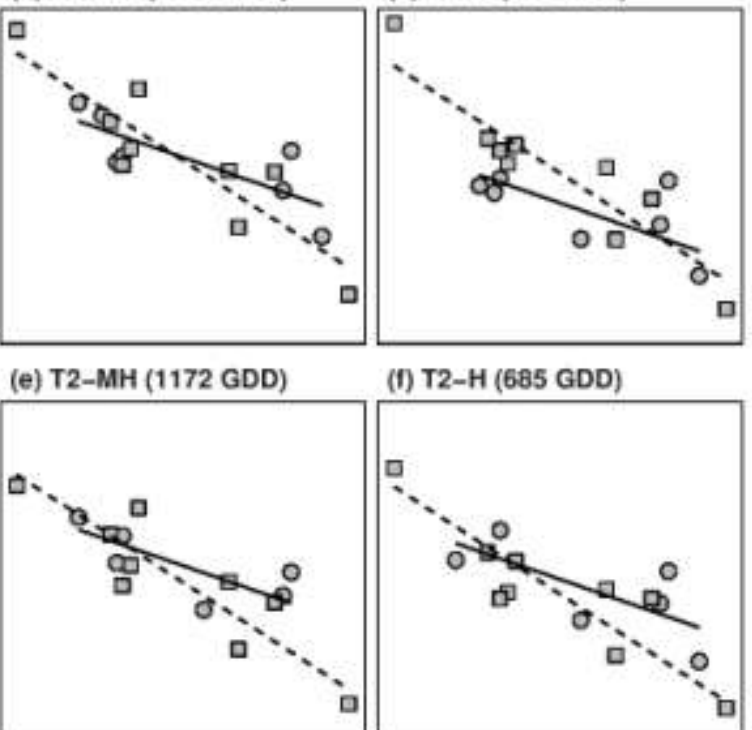

(f) T2-H (685 GDD)

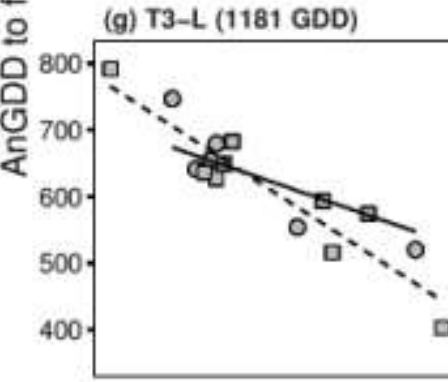

$\begin{array}{ll}\text { (h) T3-MH (866 GDD) } & \text { (i) T3-H (817 GDD) }\end{array}$
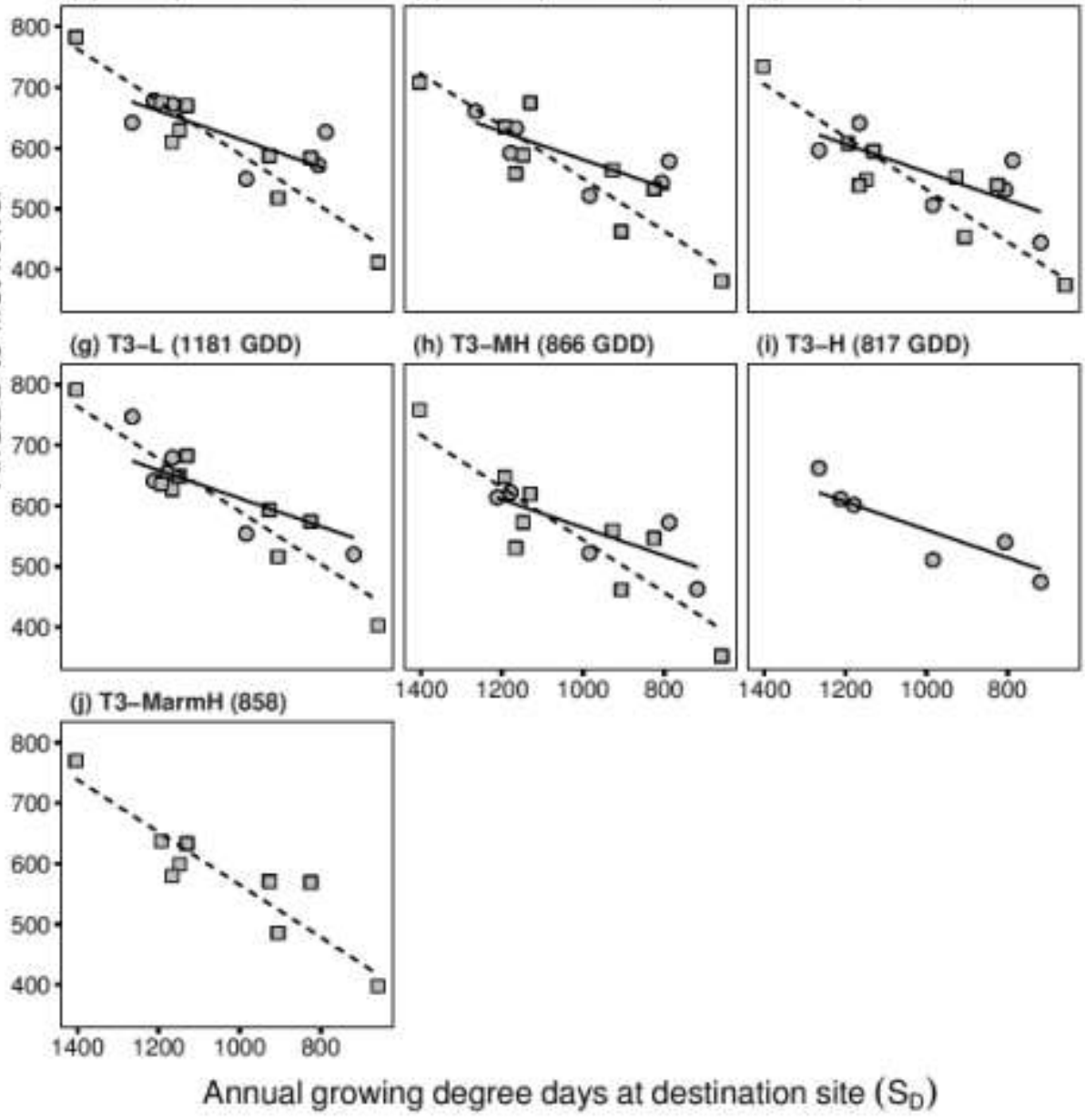

This article is protected by copyright. All rights reserved. 


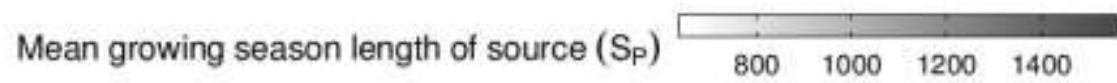

(a) AnGDD to emergence

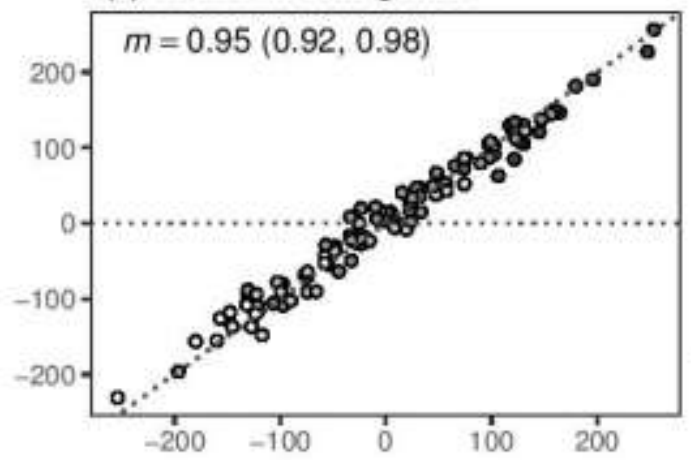

(c) AnGDD to first flower

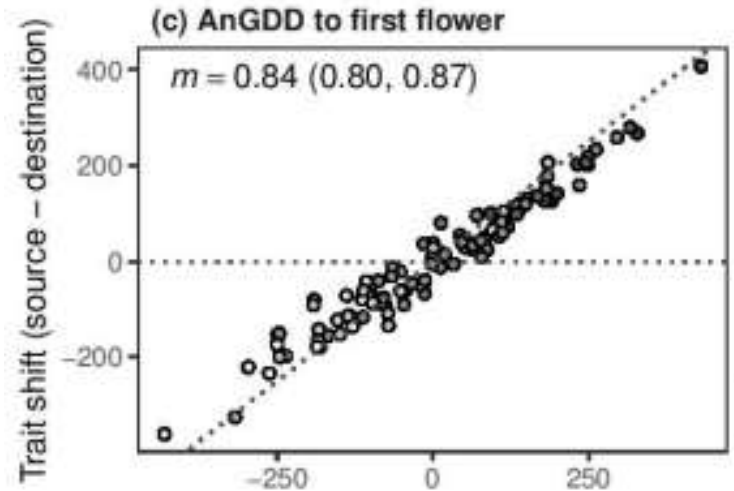

(e) AnGDD to first mature fruit

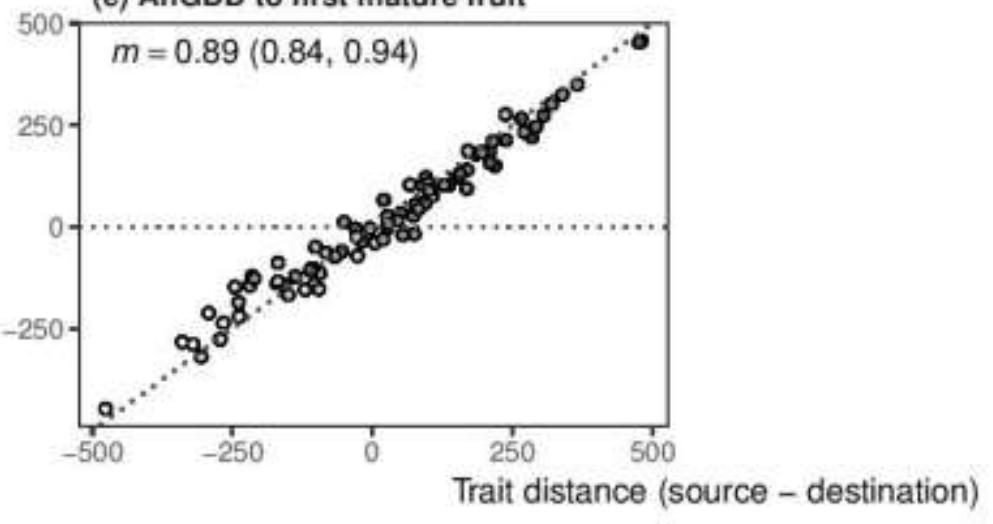

(b) Emergence to first flower

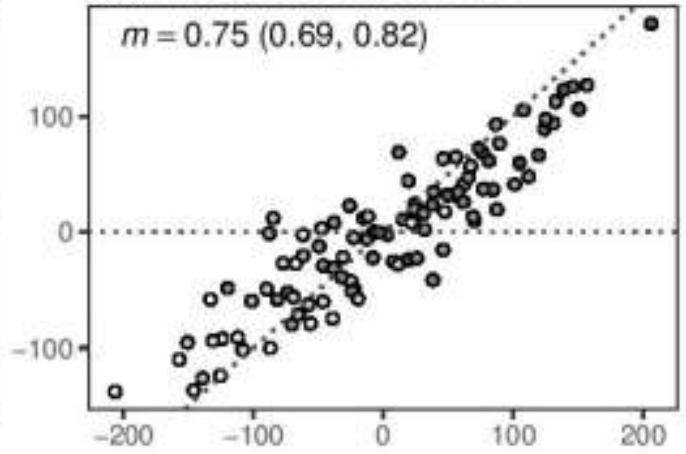

(d) First flower to first mature fruit

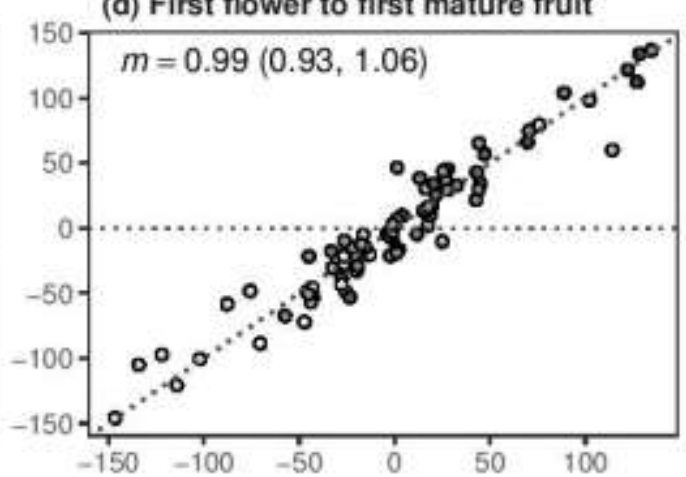


Mean season length (AnGDD) $700 \quad 900 \quad 1100 \quad 1300$

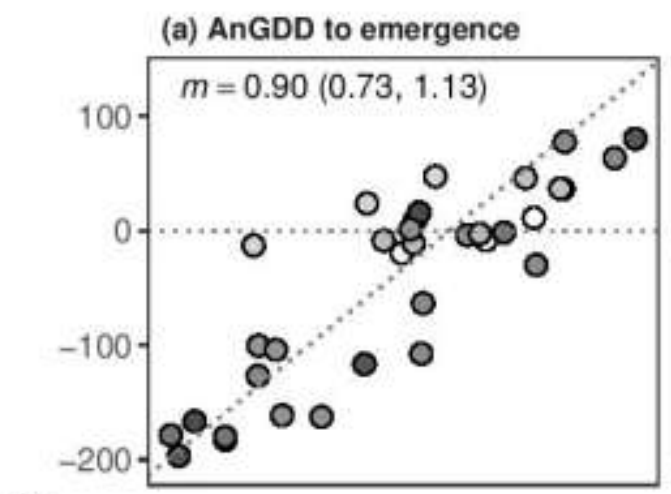

(b) Emergence to first flower
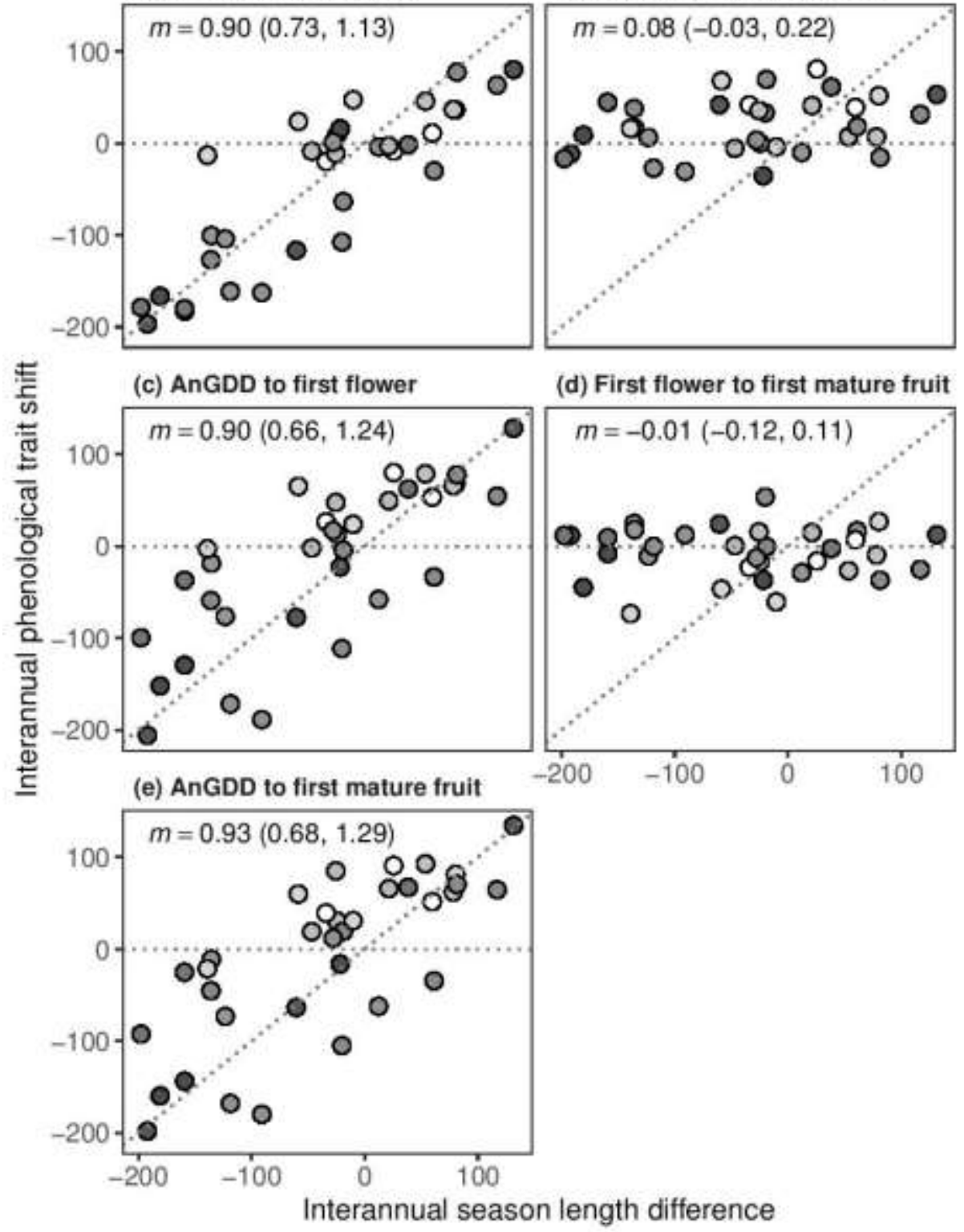

This article is protected by copyright. All rights reserved. 